University of Zurich

Department of Economics

Working Paper Series

ISSN 1664-7041 (print)

ISSN 1664-705X (online)

Working Paper No. 127

\title{
The Road not Taken: Competition and the R\&D Portfolio
}

Igor Letina

Revised version, August 2015 


\title{
The Road not Taken:
}

\section{Competition and the R\&D Portfolio}

\author{
Igor Letina*
}

\begin{abstract}
This article examines the effects of market structure on the variety of research projects undertaken and the amount of duplication of research. A characterization of the equilibrium market portfolio of $R \& D$ projects and the socially optimal portfolio is provided. It is shown that a merger decreases the variety of developed projects and decreases the amount of duplication of research. An increase in the intensity of competition among firms leads to an increase in the variety of developed projects and a decrease in the amount of duplication of research.
\end{abstract}

*University of Zurich, Department of Economics; igor.letina@econ.uzh.ch. I am grateful to Ufuk Akcigit, Paul Heidhues, Arnd Heinrich Klein, Nick Netzer, Georg Nöldeke, Daniel L. Rubinfeld, Sabrina Studer, Xavier Vives, David Wettstein, E. Glen Weyl, Fabrizio Zilibotti and to seminar participants for helpful discussions and suggestions. Special thanks are due to Armin Schmutzler for numerous suggestions and comments. Financial support of the Swiss National Science Foundation is gratefully acknowledged. 


\section{Introduction}

In 1998, the U.S. Department of Justice blocked the proposed merger of Lockheed Martin and Northrop Grumman, the largest blocked merger in the U.S. history at the time. The merger would have reduced the number of firms supplying aircraft and electronic systems to the Department of Defense from three (including Boeing) to only two. According to Robinson (1999) and Rubinfeld and Hoven (2001), one of the main reasons why the Department of Justice, supported by the Department of Defense, opposed the merger was the concern that the merger would have had negative effects on innovation. However, the issue was not so much with the amount of funds invested in innovation, the bulk of which comes from the Department of Defense anyway (Rubinfeld and Hoven, 2001). Rather, the principal concern was that reducing the number of firms in the industry would reduce the diversity of approaches to innovation.

This article develops a model where the effects of such a merger on the variety of approaches to innovation and the amount of duplicative research can be studied explicitly. From society's point of view, higher variety of research projects being developed is desirable because it increases the probability that the innovation will be discovered. On the other hand, more duplication of research projects is also desirable because it implies stronger product market competition ex post and lower deadweight loss. The market $R \& D$ portfolio is a function which captures how many firms are investing in each of the possible projects, and the variety of approaches is the fraction of projects which are developed by at least one firm. Of course, both more variety and more duplication are costly. The main object of analysis will be the market R\&D portfolio. The model will allow us to study how a change in the market structure will change the equilibrium $R \& D$ portfolio.

The main model assumes that there are $N$ symmetric firms competing in a market. In the first stage, the firms can invest in innovation. There is a set of heterogeneous research projects and firms simultaneously choose the subset they wish to develop. The innovation is assumed to be drastic ${ }^{1}$ and the discovery procedure is stochastic. All approaches are

\footnotetext{
${ }^{1}$ Innovation is drastic if whenever at least one firm innovates, firms without the innovation cannot compete. This assumption was introduced by Arrow (1962); see also Gilbert (2006). This assumption is not needed for the characterization of the equilibrium and is relaxed in Section 7.
} 
ex ante equally likely to be successful, but ex post only one approach will be successful. The approaches differ only in the cost needed to pursue them. There are no spillovers or patents. Each firm which invested in the successful approach receives the innovation whereas each firm that did not invest in the successful project receives nothing from its research. In the second stage, the firms compete on the product market either with or without the innovation.

As all approaches are ex ante equally likely to be successful, the firms have an incentive to develop only the cheapest projects. However, the number of firms developing any given project also determines the number of firms which will compete on the product market with the new technology. Thus, when choosing which projects to develop the firms face a trade off - cheaper approaches cost less to develop but will in equilibrium attract more competitors. I show that an equilibrium of the investment game always exists and that the equilibrium market $R \& D$ portfolio is uniquely determined. I provide a simple characterization of the equilibrium R\&D portfolio and show that it follows a step function - with more expensive approaches being developed by fewer firms.

The characterization of the $\mathrm{R} \& \mathrm{D}$ portfolio is then used to derive comparative statics. I show that a decrease in the number of firms weakly decreases the variety of approaches to innovation and also weakly decreases the amount of duplication. Hence, a merger leads to a weakly decreasing variety of approaches to innovation. A policy implication drawn from this analysis is that the competition authorities should take into account the negative effects of a merger on the variety of approaches to innovation, in part giving theoretical foundation to the concern expressed in the Lockheed-Northrop case. However, if a merger leads to efficiency gains, this result need not hold.

Next, I consider the effects of a change in the intensity of competition between firms. I define an increase in the intensity of competition as any exogenous change which decreases firm profits. $^{2}$ An increase in the intensity of competition is shown to increase the variety of approaches to innovation and to decrease the amount of duplication in equilibrium. Thus, an increase in the intensity of product market competition leads to more specialized R\&D portfolios. This illustrates why an increase in the intensity of competition can both

\footnotetext{
${ }^{2}$ Similar approach is taken in Schmidt (1997) and Schmutzler (2013).
} 
increase and decrease the amount of resources invested in R\&D — if the reduction in duplication of research efforts is greater than the increase in variety of research efforts, the total amount invested in $\mathrm{R} \& \mathrm{D}$ will decrease. If the opposite is true, the total amount invested in R\&D will increase.

I provide a characterization of the socially optimal $R \& D$ portfolio and compare it with the market R\&D portfolio. I derive the condition under which the market investment in the variety of research approaches is optimal, too low or too high. Similarly, I derive the condition under which the market duplication of research approaches is optimal, too low or too high. I show that in a large class of homogeneous goods models, the market will always underinvest in the variety of approaches to process innovation. This result implies that there is a role for government subsidies of R\&D. Furthermore, it implies that the subsidies should be targeted at research projects with high development costs and high potential payoffs.

The main body of the article assumes that the innovation is drastic, firms are symmetric, have unlimited budgets and use only pure strategies. I consider the effects of relaxing these assumptions in turn and show that the equilibrium structure is in general robust. In particular, the assumption that the innovation is drastic is not necessary. In Section 7, I provide a characterization of the equilibrium portfolio without assuming drastic innovation and show that it is qualitatively similar to the equilibrium portfolio when the innovation is assumed to be drastic. However, comparative statics become significantly more complex. Section 7 shows that similar comparative static results can be obtained without the drastic innovation assumption if instead additional assumptions are imposed on the reduced form payoffs.

The outline of the article is as follows. In Section 2, a brief overview of the related literature is provided. Section 3 describes the model. The equilibrium is characterized in Section 4. Comparative statics are analyzed in Section 5. The socially optimal portfolio and its relation to the market portfolio are analyzed in Section 6. In Section 7, I relax a number of assumptions made in the main body of the article. Section 8 concludes. All proofs are relegated to the appendix. Additional extensions are in the Online Appendix. 


\section{Related literature}

This article contributes to the literature on the relationship between market structure and the incentives of the firms to invest in innovation. A large part of this literature studies the amount of resources that firms invest in $R \& D$. Depending on the specifics of the model used, the literature finds that the competition in the marketplace can increase, decrease or have non-monotone effects on the amount invested in R\&D. For surveys of this vast literature see Gilbert (2006), Sena (2004) and Cayseele (1998). Vives (2008) and Schmutzler (2013) provide comprehensive studies for a range of market competition models and demand structures. Important contributions to this literature have been made from the endogenous growth literature, particularly from the models of step-bystep innovations (see for example Aghion et al. (2001) and Aghion et al. (2005)). This article contributes to this literature by providing a model which allows us to consider how the variety and duplication of approaches to research change as the market structure changes, and how it relates to the socially optimal amount of variety and duplication of research.

This article is more closely related to the part of the literature on competition and innovation that examines how competing firms choose some aspect of the research strategy. Bhattacharya and Mookherjee (1986) and Klette and Meza (1986) consider a model where undertaking research is like drawing a random variable. The maximum realization of the random variables determines the winner of the race (winner takes all) but also both private and social payoff. Firms choose a parameter of the density function, which determines the variance and in some scenarios the correlation of the research output. This parameter is interpreted as a research strategy of the firm. Dasgupta and Maskin (1987) consider a similar model. Results obtained by these models depend on the assumptions made about the distribution of research outcomes, but in a large class of cases, firms undertake excessive risk (because firms care who wins the race, whereas society only cares about the best research output; however see also Cabral (1994) and Kwon (2010) who find that the market is biased against risky research). At the same time, if reducing correlation is costly, firms will choose research strategies that are too correlated, as firms will not internalize the benefit low correlation confers to its opponent when its own research 
output is low. In this setting, the firms can choose only one research project (i.e., each firm chooses one parameter of the density function), hence these models cannot examine the variety of research projects. At the same time, in these articles the choice of correlation of the outcomes is interpreted as a measure of duplication. In the present article, duplication of research is literal — the firms can choose to pursue the same project.

Fershtman and Rubinstein (1997) study an interesting model where two players search for a treasure which is hidden in one box among a set of boxes. Each player has an endogenously chosen capacity determining the number of boxes he can examine in each period. The player that first discovers the treasure, keeps it. The research strategy is the choice of the boxes which will be examined in each period. In both this article and in Fershtman and Rubinstein (1997), the players can choose both the intensity and the location of search. However, the equilibrium predictions are different. The main result of Fershtman and Rubinstein (1997) is that the search will be completely random, whereas in this article pure strategy equilibria will always exist. The reason for this difference is that in Fershtman and Rubinstein (1997) the search continues until the treasure is found and in this article the search lasts only one period. When there are multiple search periods, there is an incentive for players preempt their opponent by searching exactly those boxes that the opponents intends to search in the next period. This incentive destroys any equilibrium in which the search is not completely random. Clearly, this incentive does not exist when search lasts only one period, in which case the choice of boxes is driven by their equilibrium net expected value. In this sense, these articles are complementary. In addition, this article is concerned with how the research incentives are affected by the market structure, which is not studied in Fershtman and Rubinstein (1997)

Chatterjee and Evans (2004) present a dynamic model where two firms are searching for an innovation in a model of a hidden treasure. There are two possible research projects and only one can yield the innovation, with the winner take all feature. However, unlike Fershtman and Rubinstein (1997) and this article, developing the "right" project yields the innovation only with some exogenously given probability. They find that the amount of correlation between research of the two firms can be too high or too low depending on 
the nature of asymmetry between the two research paths. Akcigit and Liu (forthcoming) also consider a setup with two firms and two possible avenues for research, one is more profitable (in expectation) but may result in a dead-end and another which always yields a less profitable innovation if it is researched long enough. As opposed to Chatterjee and Evans (2004) they assume that firms cannot observe which research path their competitor is pursuing and they find that firms duplicate dead-end research and at the same time leave the risky research path too early. In contrast to the present article, this strand of literature assumes that firms can research only one project at a time, so the question of the choice of variety of research projects and the amount of duplicative research does not arise. This is, however, the main focus of the present article.

Most closely related to the present article is the literature on multiproject innovation, which has been studied by Sah and Stiglitz (1987) and in the related work by Reynolds and Isaac (1992) and Farrell, Gilbert, and Katz (2003). Sah and Stiglitz (1987) assume that all projects are identical. The probability of success of any individual project depends only on the effort invested in this project and is independent of anything that might be happening with other projects. Using this setting and the Bertrand model of product market, Sah and Stiglitz (1987) show that the number of projects is invariant to the number of firms in the market, a result they refer to as the "strong invariance result." Reynolds and Isaac (1992) and Farrell, Gilbert, and Katz (2003) explore this setting further and show that the invariance result is sensitive to type of product market competition. In particular, they show that the invariance result does not hold under Cournot competition.

The main difference between this article and the literature in tradition of Sah and Stiglitz (1987) is that here projects are assumed to be heterogeneous and that more than one firm can invest in the same project. Hence, firms need to decide which projects to develop and have to do so in a strategic manner, keeping in mind which projects their competitors are developing. In this article, R\&D portfolio is the main object of interest, whereas in the Sah and Stiglitz (1987) tradition it does not appear at all. There, projects are identical and it is immaterial which projects firms or their opponents develop. Thus, the model of Sah and Stiglitz (1987) does not capture the effects of variety of projects or the duplication of projects which is the main focus of analysis here. 


\section{A model of stochastic multiproject innovation}

There are $N$ symmetric firms ${ }^{3}$ that compete in the pre-innovation market and that can invest in innovation. There is a continuum of research projects $\Omega$, but only one project $\hat{j} \in \Omega$ leads to the innovation. ${ }^{4}$ We can normalize the set of possible projects to the unit interval, that is $\Omega=[0,1)$. I assume that the successful project is drawn from the uniform distribution over the set $[0,1)$. Furthermore, each project has a fixed cost of development. Investing less than this cost means that firm will fail to develop the project and investing more will not improve the probability of the project being successful. In essence, the innovation mechanism is a lottery - developing different projects is akin to buying lottery tickets, the more lottery tickets you have the higher the probability you will win, but offering to pay more for a ticket will not increase its chances of winning. This fixed cost, fixed probability mechanism is similar to the one developed in Quirmbach (1993), the difference being that here firms can invest in multiple projects.

The projects are assumed to differ in terms of the investment cost needed to develop them. Denote the cost of developing project $j \in[0,1)$ as $C(j)$. We can view $C$ as a function such that $C:[0,1) \rightarrow \mathbb{R}^{+}$. I assume that $C$ is continuous, differentiable and strictly increasing. The fact that the function $C$ is increasing is simply a matter of ordering the projects $j$ in the right way, strictness is assumed so that marginal reasoning will yield unique results. Continuity is assumed to make the problem more tractable. Furthermore, assume $\lim _{j \rightarrow 1} C(j)=\infty$. As rewards from innovation are finite, this assumption ensures that firms will not want to invest in all possible projects. No exogenous restrictions are placed on the research budgets of firms, except in the Online Appendix B.3, which studies the consequences of limited research budgets and costly financing of research.

There are two possible levels of technology — old and new. The new technology is available only to the firms which invested in the successful innovation project, whereas the old technology is available to all firms. Let $n \leq N$ be the number of firms which developed the new technology. Denote with $R(n, N)$ the payoff of a firm with the new technology, where $n$ is the number of firms with the new technology and $N$ is the total

\footnotetext{
${ }^{3}$ Asymmetric firms are studied in Section 7.

${ }^{4}$ The stochastic mechanism used to model innovation is adapted from Acemoglu and Zilibotti (1997).
} 
number of firms. Analogously, denote with $r(n, N)$ the profits of a firm with the old technology. The difference between process and product innovations is not explicitly modeled. As long as the product market payoffs can be expressed in terms of the reward functions, the present model can be used to study both types of innovation.

Next, I list assumptions that will be used in the article. However, note that only Assumption 1 is used throughout.

Assumption 1 (Non-increasing reward to subsequent innovators). For all $N$ and $n \in\{1, \ldots, N-1\}$ it holds:

$$
R(n, N)-r(n-1, N) \geq R(n+1, N)-r(n, N) .
$$

This assumption implies that the gain from innovation does not increase as the number of innovators increases. It captures the intuition that a firm prefers that its competitors do not innovate. Thus innovations are strategic substitutes. Although intuitive, this assumption needs to be checked for each model of product market competition. The consequences of relaxing this assumption will be considered in Section 7 .

I assume that the innovation is drastic, in the sense that if there is at least one firm which has successfully developed the innovation, all firms which do not have the innovation cannot compete. That is, the laggards receive a payoff of zero and do not exert competitive pressure on the firms which have successfully innovated. For process innovations, this implies that the price of a monopolist with the innovation is below the marginal cost of any firm without the innovation. For product innovation this implies that the old product is made obsolete and it cannot be sold on the market. This assumption will be relaxed in a Section 7, where the equilibrium will be characterized for non-drastic innovations and robustness of comparative static effects will be discussed. In the notation used here we have:

Assumption 2 (Drastic innovation).

For all $n, N$ and $N^{\prime}$ such that $1 \leq n \leq N \leq N^{\prime}$ it holds: $(i) r(n, N)=0$ and (ii) $R(n, N)=R\left(n, N^{\prime}\right)$.

Expression $(i)$ ensures that laggards have zero profits and $(i i)$ ensures that laggards 
do not exert competitive pressure on the innovators. Under Assumption 2, $R(n, N)$ is constant for any $N$, so from now on just $R(n)$ will be used to indicate the payoff of an innovator when there are $n$ innovators. Furthermore, if Assumption 2 holds then Assumption 1 simplifies to the following two conditions: $R(n) \geq R(n+1)$ for all $n \geq 1$ and $R(1)-r(0, N) \geq R(2)$. The first expression states that the payoff per innovator weakly decreases as the number of innovators increases. The second expression states that the incentives of a prospective monopolist are greater than those of a single innovator when two firms innovate.

Assumption 3. For every $N$ it holds: $r(0, N) \geq r(0, N+1)$.

This assumption states that as the number of firms which are active in the preinnovation market increases, the profits of each individual firm do not increase. The intuition is simple: the additional firm will either not be competitive and have no effect on the profits of other firms, or it will put competitive pressure on other firms and decrease their profits, but it cannot increase their profits.

The unmodeled product market game that determines payoffs to the firms, $R(n, N)$ and $r(n, N)$, also determines the consumer surplus. This consumer surplus is the result of the competition among $N$ firms, $n$ of which have the new technology, and who face some demand curve on the product market. Denote this consumer surplus in reduced form with $C S(n, N)$. Then, the social welfare, when there are $n$ innovators, is the sum of consumer and producer surplus: $W(n)=C S(n, N)+n R(n, N)+(N-n) r(n, N) .^{5}$ That is, $W(0)$ denotes the welfare without the innovation, $W(1)$ denotes the welfare when there is only one firm with the innovation, and so on.

Assumption 4 (Non-increasing welfare returns).

For every $n \in\{1, \ldots, N-1\}$ it holds $W(n)-W(n-1) \geq W(n+1)-W(n)$.

Each firm is assumed to be risk neutral and to maximize its expected profits. Profit maximization requires that firms either invest zero in a project or exactly the amount that is required to open the project. Thus, we can identify the strategy of a firm simply by the set of the projects in which it invests. Denote the strategy of a firm $i$ with $I_{i}$ and

\footnotetext{
${ }^{5}$ We can suppress the dependence of $W$ on $N$ as $N$ will be fixed whenever welfare is analyzed.
} 
call it the investment plan of firm $i$. In principle, $I_{i}$ could be any measurable subset of the unit interval or the empty set. To simplify exposition, assume that unless it is empty, the set $I_{i}$ consists only of a finite number of intervals, each closed from below and open from above. ${ }^{6}$ Formally, the strategy space of firm $i$ is the set $\mathcal{I}_{i}$ where:

$$
\mathcal{I}_{i}:=\left\{I_{i} \subset[0,1): I_{i}=\cup_{k=1}^{\bar{k}}\left[a_{k}, b_{k}\right)\right\} \cup\{\emptyset\},
$$

for $\bar{k} \in \mathbb{N}$ and $0 \leq a_{k}<b_{k}<1$ for all $k \in\{1, \ldots, \bar{k}\}$.

In particular, note that this assumption ensures that the investment plan will not contain any isolated zero-mass points.

Let $I=\left[I_{1}, \ldots, I_{N}\right]$ be a vector of investment plans of all $N$ firms. Define the function indicating the number of firms investing in a project, given a vector of investment plans $I$, as $n(j, I):[0,1) \rightarrow \mathbb{N}^{0}$ as:

$$
n(j, I)=\sum_{i=1}^{N} \mathbf{1}\left(j \in I_{i}\right),
$$

where $\mathbf{1}(\cdot)$ is the indicator function.

Let $I_{i}^{c}:=[0,1) \backslash I_{i}$. The expected profit of a firm $i$ is then

$$
\pi_{i}(I)=-\int_{I_{i}} C(j) d j+\int_{I_{i}} R(n(j, I)) d j+\int_{I_{i}^{c}} r(n(j, I), N) d j
$$

The first part of the equation above represents the investment costs of firm $i$, the second part gives the expected profits from the new technology, whereas the third part gives the expected profits from the old technology. By Assumption 2, $r(n(j, I), N)=0$ whenever $n(j, I)>0$. However, it will be positive whenever $n(j, I)=0$, which will occur in equilibrium with positive probability. ${ }^{7}$

When $N=1$, that is, when there is a monopolist in the market, the above becomes

\footnotetext{
${ }^{6}$ Because adding or removing zero-mass points does not change the payoff of any of the firms, allowing $I_{i}$ to be general would mean that all statements regarding the properties of the equilibrium would have to be qualified by "almost everywhere". This assumption does not affect the mechanics of the model. For any measurable investment plan $I_{i}$ which does not satisfy the assumption above, there always exists plan $I_{i}^{\prime}$ which does satisfy the assumption and only differs from $I_{i}$ by zero-mass points, hence delivers the same payoff to all firms.

${ }^{7}$ Furthermore, the magnitude of $r(0, N)$ will determine the strength of the Arrow replacement effect, which is crucial for the equilibrium variety of research projects.
} 
a pure maximization problem. When there are more firms in the market we have to consider the effects of strategic interaction among firms. Specifically, $n(j, I)$ depends on the actions of other firms and thus the expected profit of one firm depends on the actions of other firms.

Finally, assume that investment in innovation is profitable. That is $R(1)-r(0, N)>$ $C(0)$. This assumption guarantees positive investments in the equilibrium. If this assumption was not met, even the monopolist's return on the investment in the cheapest project would not justify its cost. As $C(j)$ is strictly increasing and rewards are non-increasing in $n$, then no project could be profitable. Thus, if this assumption failed there would be a simple equilibrium in which firms did not invest at all.

The model is developed and analyzed in general terms. In the appendix A.10, I provide an example with three firms, process innovation and Cournot competition, which shows how the general model can be applied to a more specific setting. In the example, I analyze the effects of a merger, a switch from Cournot to Bertrand competition as well as compare the market portfolio of $\mathrm{R} \& \mathrm{D}$ projects with the socially optimal portfolio.

\section{Equilibrium}

The vector of investment plans summarizes all decisions of all firms that are relevant for this problem. A vector of investment plans $I^{*}$ is a pure strategy equilibrium (PSE) if no firm can increase its expected profit by unilaterally choosing an alternative investment plan $I_{i}^{\prime}$. That is $I^{*}$ is a pure strategy equilibrium if, for any firm $i$, there does not exist an investment plan $I_{i}^{\prime}$ such that $\pi_{i}\left(I_{i}^{\prime}, I_{-i}^{*}\right)>\pi_{i}\left(I^{*}\right)$. In the main text, I will only consider pure strategy equilibria. Mixed strategy equilibria exist and are considered in a special case in the Online Appendix B.2. As it is shown there, the insights from pure strategy equilibria, both in terms of the structure of the equilibrium and the comparative static effect, are robust.

Proposition 1 (Existence, non-uniqueness and equivalence of equilibria). Suppose that Assumption 1 holds. Then:

1. A pure strategy equilibrium always exists. 
2. If $I^{*}$ is a PSE and $0<n\left(j, I^{*}\right)<N$ for some $j \in[0,1)$, then infinitely many PSE exist.

3. If there are multiple PSE they all result in the same market portfolio of research projects. That is, if $I_{1}^{*}$ and $I_{2}^{*}$ are PSE investment plans, then $n\left(j, I_{1}^{*}\right)=n\left(j, I_{2}^{*}\right)$ for all $j \in[0,1)$. Furthermore, if $I_{1}^{*}$ is a PSE then any investment plan $I_{3}^{*}$ such that $n\left(j, I_{1}^{*}\right)=n\left(j, I_{3}^{*}\right)$ for all $j \in[0,1)$ is also a PSE.

An equilibrium in pure strategies will always exist. However, typically there will also exist infinitely many equilibria. The proof of statement 2 in Proposition 1 (see the Appendix A.1) reveals the nature of the multiplicity. In equilibrium, identities of firms investing in any given project are in general not determined, only the number of firms investing is determined. Only when either all firms invest in a project or no firm invests in a project, we can infer the behavior of individual firms. Thus, when $0<n\left(j, I^{*}\right)<N$ for some $j \in[0,1)$, there are projects for which the identities of firms investing are not determined and as there is an infinite number of ways to assign investments to firms, there must be infinitely many equilibria.

Statement 3 of Proposition 1 clarifies this point further. It states that every equilibrium induces the same market portfolio of research projects - that is in every equilibrium the set of developed projects will be the same and the number of firms investing in each project will be the same. Thus, although there is a multiplicity of equilibria, the equilibrium market portfolio is unique. As firms are identical, welfare does not depend on the identity of firms doing research. From the social welfare perspective, any two equilibria are equivalent.

Furthermore, not only do all equilibria induce the same market portfolio of research projects, but any investment that induces the equilibrium portfolio is itself an equilibrium. The intuition for this result is straightforward - the profitability of any research project depends only on the cost of the project and the number of competitors who are investing in the same project. In particular, it does not depend on any other investment that the firm or its competitors may be making. Hence, if in an equilibrium all profitable investments are exhausted and no unprofitable investments are made, then any other investment plan that prescribes the same investment portfolio in the same manner exhausts all profitable 
investments and has no superfluous investments.

Statement 3 of Proposition 1 implies that if $I^{*}$ is an equilibrium then the function $n\left(j, I^{*}\right)$ fully characterizes the equilibrium portfolio of research projects. As $n(j, \cdot)$ is the same for any equilibrium, we can denote the function characterizing the equilibrium portfolio of research projects as $n^{*}(j)$. Using the equilibrium constructed in the proof of statement one of Proposition 1 and applying Assumption 2 yields the following result.

Proposition 2 (Characterization of equilibrium portfolio).

Suppose that Assumptions 1 and 2 hold. Denote with $m$ the maximum number of firms investing in any project:

$$
\begin{gathered}
m=\max _{\{1, \ldots, N\}} n \\
\text { s.t. } R(n)-r(n-1, N)-C(0)>0
\end{gathered}
$$

and with $\alpha_{k}$ for $k \in\{1,2, \ldots, m\}$ the most expensive project in which $k$ firms can profitably invest. That is:

$$
\begin{gathered}
R(1)-r(0, N)-C\left(\alpha_{1}\right)=0 \\
R(2)-C\left(\alpha_{2}\right)=0 \\
\vdots \\
R(m)-C\left(\alpha_{m}\right)=0 .
\end{gathered}
$$

Let $\alpha_{m+1}=0$ and $\alpha_{0}=1$. Then the PSE portfolio $n^{*}(j)$ is given by

$$
n^{*}(j)=k \quad \text { if } \quad j \in\left[\alpha_{k+1}, \alpha_{k}\right) .
$$

An illustration of the equilibrium market portfolio for $N=3$ and a process innovation in a Cournot market (which is the example from the appendix A.10) is provided in Figure 1. Here, $m=3$ represents the maximum number of firms that can profitably invest in any project. Because project 0 is by assumption the cheapest to develop, then $m$ firms will invest in this project. Each point $\alpha_{k}$ is constructed so that, at the margin, if $k$ firms invested the profit from investment would be zero. As $C(j)$ is assumed to be strictly 


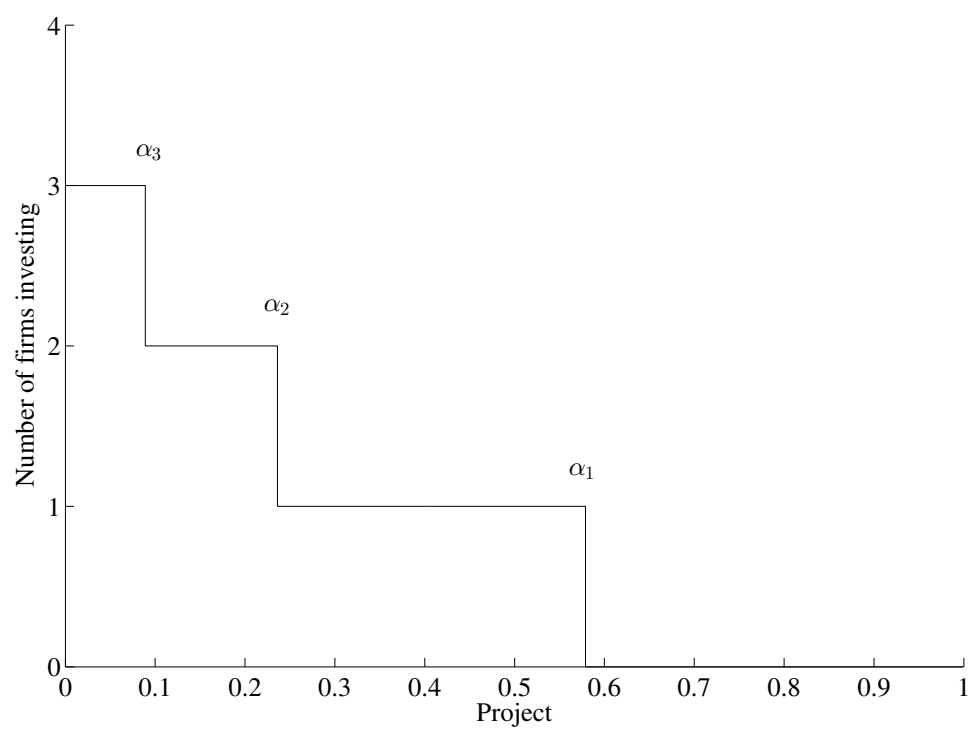

Figure 1: Equilibrium market portfolio.

increasing, then at any point $j>\alpha_{k}$ strictly fewer than $k$ firms can profitably invest. As rewards are finite and costs to innovation approach infinity as $j \rightarrow 1$, values $\alpha_{1}, \alpha_{2}, \ldots, \alpha_{m}$ always exist. Furthermore, as $C(j)$ is increasing and by Assumption 1 the rewards to innovation are non-increasing it is easy to see that $\alpha_{1} \geq \alpha_{2} \geq \cdots \geq \alpha_{m}{ }^{8}$. From this observation it follows directly that the function $n^{*}(j)$ is weakly decreasing.

It is interesting to note that the present model would be equivalent to the level-ofinvestment models if (i) the successful project was drawn for each firm separately and (ii) the draws were independent. In such a setting, a firm would have no incentive to choose more expensive R\&D projects. Thus, in equilibrium, all firms would invest in some interval of $\mathrm{R} \& \mathrm{D}$ projects $[0, j)$, where investing in a marginal project increases the probability of discovering the innovation at the marginal cost $C(j)$. In such a setting duplication of research and variety of research would be meaningless.

The set of all projects the market invests in is $\left[0, \alpha_{1}\right)$. Thus, I will refer to $\alpha_{1}$ as the variety of research projects undertaken. I will say that the variety of research projects increases if $\alpha_{1}$ increases. The probability that the market develops an innovation is equal to $\alpha_{1}$. Hence an increase in the variety of research projects implies an increase in the

\footnotetext{
${ }^{8}$ Note that the inequality is weak (because the inequality in Assumption 1 is weak), so that it might happen for some $k \leq m$ that $\alpha_{k}=\alpha_{k+1}$. In this case, define $\left[\alpha_{k+1}, \alpha_{k}\right)=\emptyset$. Thus there will be no project that exactly $k$ firms will develop.
} 
probability that the market will develop an innovation. The function $n^{*}(j)$ captures the number of firms investing in any given project $j$ in equilibrium. Hence, I will refer to the number $n^{*}(j)$ as the market amount of duplication of project $j$.

\section{Comparative statics}

In this section, I will study how the market portfolio of research projects changes as the market structure changes. In particular, I will look at how a change in the number of active firms in the market and the intensity of competition among them affects the market portfolio of research projects. As can be seen from Proposition 2, the equilibrium portfolio is characterized by the maximum number of firms $m$ investing in any project and the $k$-firm frontiers $\alpha_{k}$, for $k \in\{1, \ldots, m\}$. I will analyze how a change in $N$ and a change in the intensity of competition affect these variables.

\section{Change in the number of firms}

Consider first the case where the number of active firms in the market changes, but all other characteristics of the market remain the same.

Proposition 3 (Increase in the number of firms).

Suppose that Assumptions 1, 2, and 3 hold. Let the number of firms in the pre-innovation market increase from $N$ to $N^{\prime}$ so that the PSE investment plan changes from I to $I^{\prime}$.

1. In PSE, the variety of projects developed and the probability of developing an innovation weakly increases, that is $\alpha_{1} \leq \alpha_{1}^{\prime}$.

2. The maximum number of firms investing also increases, that is $m \leq m^{\prime}$.

3. Apart from the increase in variety of projects developed and in the maximum number of firms investing, the PSE portfolio remains the same. That is, $n(j, I)=n\left(j, I^{\prime}\right)$ for all $j \in[0,1) \backslash\left\{\left[0, \alpha_{m^{\prime}}^{\prime}\right] \cup\left[\alpha_{1}, \alpha_{1}^{\prime}\right]\right\}$.

If a firm innovates, it replaces its profits without the innovation with the profits with the innovation. Thus, holding everything else equal, the larger the pre-innovation profits 
of firms, the weaker its incentive to innovate. The increase in the variety of developed projects is driven solely by the Arrow replacement effect. In this setting, the firm investing near $\alpha_{1}$ replaces $r(0, N)$ with $R(1)$. As $r(0, N) \geq r(0, N+1)$, the Arrow replacement effect is weaker when there are $N+1$ firms in the market. Consequently, firms attempt to escape the competition by investing in more expensive research projects than before and the variety of developed projects increases. This is equivalent to saying that the probability of discovering an innovation increases.

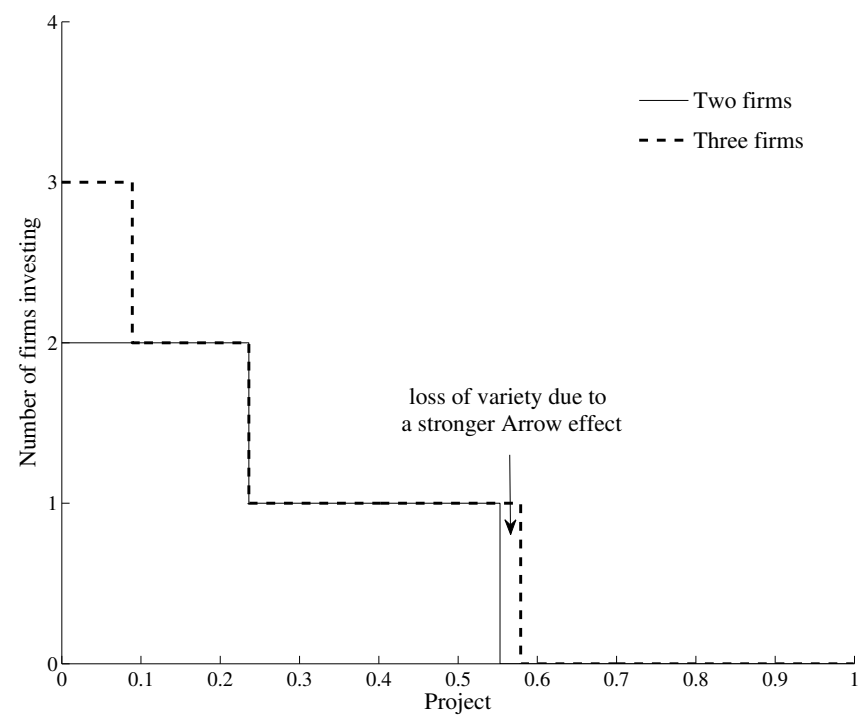

Figure 2: Merger in a 3-firm Cournot market.

An increase in the number of active firms weakens the Arrow replacement effect both in this model and in the usual level-of-investment models. A difference, however, arises in the effect on the ex post profits of firms. Here the firms are free to choose in which projects to invest. The number of firms investing in any given project, and hence the ex post number of competitors, is endogenously determined. Following Vives (2008), call the reduction in innovation incentives due to competition ex post as the Schumpeter effect. Then, the Schumpeter effect in this model does not change as the number of ex ante active firms changes (except in those cases where the number of firms ex post was limited by the number of active firms). This leads to the clear effect of an increase in the number of firms on the variety of projects developed, as only one firm will invest in the most expensive projects. 
Consider in this context the invariance result of Sah and Stiglitz (1987), which states that the number of research projects is invariant to the number of firms in the market. The invariance can only hold if $r(0, N)=r(0, N+1)$, that is, only if the Arrow replacement effect is constant. Clearly this will hold under homogeneous goods Bertrand competition as Sah and Stiglitz (1987) have originally assumed, because $r(0, N)=0$ for any $N \geq 2$. Conversely, it will not hold (in general) under Cournot competition as $r(0, N)$ will be decreasing in $N$, which is in line with the results derived in Reynolds and Isaac (1992) and Farrell, Gilbert, and Katz (2003).

\section{Merger analysis}

One implication of this result is that a merger in an imperfectly competitive industry will potentially lead to a loss of variety of approaches to innovation (see Figure 2). Thus, competition authorities should take this loss of variety of approaches to innovation into account when reviewing merger cases, especially if innovation is important in the industry, as it was in the proposed Lockheed-Northrop merger. ${ }^{9}$ As the loss of the variety of approaches to innovation is driven by the Arrow replacement effect, the magnitude of the loss of variety will be proportional to the increase in profits (in the market without the innovation) due to the merger.

This result depends on the assumption that the merger merely reduces the number of active firms in the industry, without changing the production or the innovation cost functions of the merged firms. ${ }^{10}$ However, if the merged firm is more efficient than the individual firms, then this efficiency gain can outweigh the anti-competitive effects of the merger. As a matter of fact, U.S. Department of Justice and the Federal Trade Commission (2010) Horizontal Merger Guidelines explicitly recognize this efficiency defense when analyzing the effects of mergers on innovation. ${ }^{11}$

The result in Proposition 3 shows that a merger can lead to a decrease in the variety of approaches to innovation. Two extensions I develop in the Online Appendix (Section B.1)

\footnotetext{
${ }^{9}$ For details see Robinson (1999) and Rubinfeld and Hoven (2001).

${ }^{10} \mathrm{I}$ would like to thank an anonymous referee for this point.

11 "When evaluating the effects of a merger on innovation, the Agencies consider the ability of the merged firm to conduct research or development more effectively." See Section 10 of the Guidelines.
} 
show how this result can be overturned if the merger in question leads to efficiency gains. The first extension (Proposition 7) supposes that the merged firm can invest in innovation at a lower cost than its competitors. Importantly, the efficiency is not dependent on the identity of the merging firms. Proposition 7 shows that, for a general specification of cost efficiencies, a pure strategy equilibrium exists, the variety of approaches developed in equilibrium is uniquely determined and the variety does not decrease in the post-merger market if the efficiency is large enough. The second extension (Proposition 8) considers an alternative form of efficiency gains. There, the efficiencies depend on the identities of merging firms, so that each merger reduces the cost of innovation in a merger-specific interval of approaches to innovation. Proposition 8 shows that also in this setting a pure strategy equilibrium exists and the variety of approaches developed in equilibrium is uniquely determined. However, in this case it is not sufficient for the efficiency gains to be large enough. In order for such a merger to not decrease the variety of approaches to innovation, the merger has to be of the right kind - namely, the efficiency gains must affect those approaches to innovation which would not have been developed in the absence of the efficiency gains.

These results suggest that a merger in a highly innovative but imperfectly competitive industry might lead to a decrease in the variety of approaches to innovation, as has been suggested in the Lockheed-Northrop case. Thus, the competition authorities should take this potential effect into account when reviewing merger applications. At the same time, if a merger would lead to efficiency gains which are large enough and of the right kind, the merger need not decrease variety and could even lead to an increase in the variety of approaches to innovation. Thus, an efficiency defense should be considered also in the case where the effect of the merger on variety of approaches to innovation is a cause for concern.

\section{Change in the intensity of competition}

The competitive structure of the market is not only determined by the number of firms which are active in the market, but also by the intensity of competition among firms. Suppose that there are two sets of reward functions $\{R, r\}$ and $\left\{R^{\prime}, r^{\prime}\right\}$ such that $R(n)>$ 
$R^{\prime}(n)$ for every $n>1, R(1)=R^{\prime}(1)$ and $r(0, N)>r^{\prime}(0, N)$. Then we can interpret the move from $\{R, r\}$ to $\left\{R^{\prime}, r^{\prime}\right\}$ as an increase in the intensity of competition. Most standard examples of an increase in the intensity of competition correspond to this definition. In particular, in the appendix A.10 I will consider a move from Cournot to Bertrand type of competition, but models of differentiated Cournot/Bertrand also correspond to this definition. The next result considers the effect of an increase in the intensity of competition on the market R\&D portfolio.

Proposition 4 (Increase in the intensity of competition).

Suppose that Assumptions 1 and 2 hold. Let $N \geq 2$ and suppose the intensity of competition increases so that the PSE investment plan changes from I to $I^{\prime}$. Then the variety of research projects undertaken and the probability of discovering the innovation increase. That is $\alpha_{1}<\alpha_{1}^{\prime}$. The amount of duplication of research decreases. That is for each $j$ such that $n(j, I) \geq 2$ we have $n(j, I) \geq n\left(j, I^{\prime}\right)$ with $n(j, I)>n\left(j, I^{\prime}\right)$ for at least some projects.

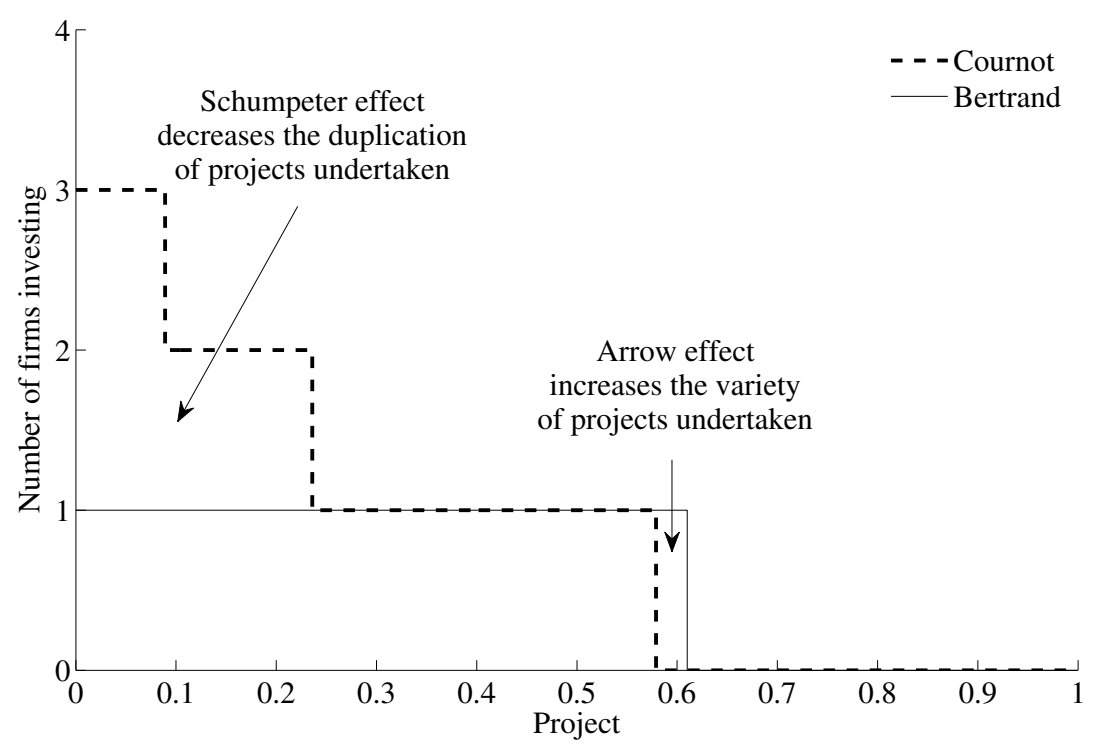

Figure 3: An illustration of an increase in intensity of competition.

An increase in the intensity of competition decreases the profits firms receive if no firm successfully innovates, thereby weakening the Arrow replacement effect and leading to an increase in the variety of developed research projects. On the other hand, it also decreases payoffs to firms if there are multiple innovators, leading to a (weakly) decreasing 
number of firms investing in duplicative research projects. An increase in the intensity of competition "flattens out" the equilibrium research portfolio, reducing the duplication of costs (see Figure 3). However, it is not clear that an increase in the intensity of competition will lead to higher social welfare. On the one hand, duplication of costs is reduced and the variety of research projects is increased. On the other, less duplication of costs also implies fewer firms (though competing more vigorously!) in the product market leading to a possible efficiency loss. Which effect prevails will depend on the exact specification of the product market competition and the demand function.

An increase in the number of firms is sometimes used as a way to model an increase in the intensity of competition. The preceding results highlight the difference between an increase in the number of firms and an increase in the intensity of competition as defined here. An increase in the intensity of competition reduces firm profits whenever there are multiple firms competing. That is, it reduces firm profits both ex ante and ex post. The number of firms, due to the endogeneity of the ex post market structure, affects firm profits only ex ante. Thus, the Schumpeter effect is present only in the case of an increase in the intensity of competition and not in the case of an increase in the number of firms.

\section{Optimal portfolio}

There are several reasons to suspect that a market $R \& D$ portfolio will not be optimal. When the innovator cannot appropriate the entire surplus because a part of the surplus is captured by the consumers, the incentive to innovate may be too low. On the other hand, if innovation enables firms to become more competitive in the market and steal business from their competitors, the incentive to innovate may be too high. ${ }^{12}$ However, as this article argues, looking solely at the levels of investment in innovation is misleading. Rather, the question to be posed is whether the market invests in the optimal variety of projects and whether it optimally duplicates projects. That is, the question is how the market R\&D portfolio compares to the socially optimal portfolio.

\footnotetext{
${ }^{12}$ For an example of the under- and over-investment in innovation due to the two effects outlined here see Bester and Petrakis (1993).
} 
The approach here is to ask what is the $R \& D$ portfolio that maximizes the expected social welfare. That is, the social planner can determine the $R \& D$ portfolio, but given the portfolio the firms will be profit maximizing. In particular, firms do not share the results of research, so some duplication of research will be optimal, as duplication of the successful project implies higher product market efficiency ex post.

Recall that $W(n)$ denotes the social welfare generated by the product market if there are $n$ firms with the new technology, for every $n \leq N$. That is, $W(0)$ is welfare if no firm has successfully innovated and $W(N)$ is welfare if all firms have the new technology. The welfare is the sum of consumer surplus and producer surplus, that is $W(n)=C S(n)+$ $n R(n, N)+(N-n) r(n, N)$.

Analogously to Proposition 2, the optimal portfolio is characterized:

Proposition 5 (Characterization of the optimal portfolio).

Suppose that Assumption 4 holds. Denote with $m^{\circ}$ the optimal number of firms developing the least expensive project:

$$
\begin{gathered}
m^{o}=\max _{\{1, \ldots, N\}} n \\
\text { s.t. } W(n)-W(n-1)-C(0)>0
\end{gathered}
$$

and with $\alpha_{k}^{o}$ for $k \in\{1,2, \ldots, m\}$ the most expensive project in which at most $k$ firms can optimally invest. That is:

$$
\begin{gathered}
W(1)-W(0)-C\left(\alpha_{1}^{o}\right)= \\
W(2)-W(1)-C\left(\alpha_{2}^{o}\right)= \\
\vdots \\
W\left(m^{o}\right)-W\left(m^{o}-1\right)-C\left(\alpha_{m}^{o}\right)=0 .
\end{gathered}
$$

Let $\alpha_{m+1}^{0}=0$ and $\alpha_{0}^{o}=1$. Then the optimal portfolio $n^{o}(j)$ is given by

$$
n^{o}(j)=k \quad \text { if } \quad j \in\left[\alpha_{k+1}^{o}, \alpha_{k}^{o}\right) .
$$




\section{Market investment in variety}

It is now possible to directly compare the market $R \& D$ portfolio with the optimal portfolio. In this way it is possible to identify if and how the market portfolio differs from the optimum and to suggest a way in which a policy intervention can improve the market outcome.

The net externality from investing in marginal variety (a research project that is not developed by any other firm) is given by:

$$
\sigma=-(N-1) r(0, N)+[C S(1)-C S(0)]
$$

The first expression captures the negative externality imposed on the competitors of the firms making the marginal investment. They lose the profits they would obtain if no firm invested in the marginal project and the marginal project turned out to be successful. The second expression captures the positive externality imposed on the customers - who receive the surplus associated with one firm innovating as opposed to the surplus associated without innovation. Corollary 1 states that the optimality of investment variety depends on the sign of the net externality imposed by the marginal variety.

Corollary 1 (Market investment in variety).

Suppose that assumptions 1, 2 and 4 hold. Then the market will underinvest in the variety of $R \& D$ projects if and only if $\sigma>0$. The market will invest in the optimal variety of $R \mathscr{E} D$ projects if and only if $\sigma=0$. The market will overinvest in the variety of $R \mathscr{E} D$ projects if and only if $\sigma<0$.

In principle the sign of $\sigma$ should be checked for each model. However, as will be shown later, in a large class of homogeneous goods models the assumption that the innovation is drastic implies that $C S(1) \geq W(0) \geq C S(0)+(N-1) r(0, N)$. Thus, the market will in this case underinvest in the variety of $R \& D$ projects. The intuition for this is as follows. A process innovation is drastic if the monopolist's price is below the marginal cost of production without the innovation. Hence, consumer surplus with a monopolist (i.e., $C S(1)$ ), which is equal to the difference between the reservation price and the price paid, is greater than total welfare without the innovation (i.e., $W(0)$ ), which is equal to 
the difference between the reservation price and the cost of production.

To illustrate the market underinvestment in variety, consider a simple homogeneous product market similar to the one analyzed in Mankiw and Whinston (1986). Suppose that the inverse market demand function is given by $P(Q)$, where $Q$ is the aggregate output in the market and $P^{\prime}(Q)<0$ for all $Q$. There are $N$ symmetric firms, each of which possesses a technology given by the cost function $\bar{c}(q)$, where $\bar{c}(0)=0, \bar{c}^{\prime}(\cdot) \geq 0$ for all $q \geq 0$. Firms can invest in R\&D to develop a drastic process innovation, in which case their technology is given by the cost function $\underline{c}(q)$, where $\underline{c}(0)=0, \underline{c}^{\prime}(\cdot) \geq 0$ for all $q \geq 0$. A process innovation is drastic if a monopolist facing the cost function $\underline{c}(q)$ chooses a price which is below the marginal cost of production of a firm with the old technology. Formally, an innovating monopolist would choose a quantity $q_{1}$ such that $P\left(q_{1}\right)<\bar{c}^{\prime}(0)$.

Proposition 6 (Underinvestment in homogeneous product markets).

Suppose that Assumptions 1, 2 and 4 hold. Then an industry à la Mankiw and Whinston with a potential drastic process innovation always underinvests in the variety of $R \mathscr{E} D$ projects.

As the case of homogeneous product market illustrates, a decentralized market will tend to underinvest in drastic innovations. It should be noted that the critical assumption in this example is not the type of the product market competition. Rather, it is the assumption that the innovation is drastic which drives the result.

Proposition 6 offers insights relevant to research policy. Suppose that society cannot affect the market structure or the behavior of firms in the market but can offer subsidies for research. The market will tend to underinvest in the variety of drastic innovation by failing to develop high-cost projects which should optimally be developed. Thus, the research subsidies should be directed toward research projects with (1) high costs; and (2) and high potential payoffs.

\section{Market investment in duplication}

Typically, the market R\&D portfolio will involve some duplication of research projects. As this is duplication of identical projects, it does not increase the probability that an 
innovation will be discovered. However, duplication is not entirely wasteful either. If multiple firms develop the same project and this project turns out to be the successful one, then there will be more competitors on the product market. So for the cost of duplicating research the society receives the (weakly) higher product market efficiency. The efficient duplication of R\&D projects is captured by the optimal portfolio.

In equilibrium, a firm duplicating a research project imposes both negative externalities on its competitors (in the form of business stealing effect) and positive externalities on the consumers (in the form of the efficiency effect). Define the net externalities effect of the $k$-th duplication as:

$$
\delta(k)=[(k-1)(R(k)-R(k-1))]+[C S(k)-C S(k-1)] .
$$

The first bracket captures the negative externalities generated by the investment of the $k$-th innovator, which are the reduction of profits of $k-1$ firms from $R(k-1)$ to $R(k)$. The second bracket captures the positive externalities which accrue to the consumers, and which are captured by the difference between $C S(k)$ and $C S(k-1)$, the consumer surplus when there are $k$ competitors and $k-1$ competitors on the product market, respectively.

Corollary 2 (Market investment in duplication).

Suppose that Assumptions 1, 2 and 4 hold. Denote with $m$ the maximum number of firms investing in the market equilibrium and with $m^{o}$ the maximal number of firms investing in the optimal equilibrium. For $2 \leq k \leq \min \left\{m, m^{o}\right\}$, denote with $\alpha_{k}$ the $k$-firm frontiers in the market portfolio and with $\alpha_{k}^{o}$ the $k$-firm frontiers in the optimal portfolio.

If $\delta(k)<0$ then $\alpha_{k}^{o}<\alpha_{k}$ and the market overinvests in duplication of all projects $j \in\left(\alpha_{k}^{o}, \alpha_{k}\right)$. If $\delta(k)>0$ then $\alpha_{k}<\alpha_{k}^{o}$ and the market underinvests in duplication of all projects $j \in\left(\alpha_{k}, \alpha_{k}^{o}\right)$. If $\delta(k)=0$ then $\alpha_{k}^{o}=\alpha_{k}$ and the market optimally invests in duplication of all projects in the neighborhood of $\alpha_{k}$.

If $m \geq m^{o}$ and $\delta(k) \geq 0$ for all $k \in\left\{2, \ldots, m^{o}\right\}$, then the market (weakly) overinvests in duplication of all R\&D projects. Conversely, if $m \leq m^{o}$ and $\delta(k) \leq 0$ for all $k \in$ $\{2, \ldots, m\}$, then the market (weakly) underinvests in duplication of all R\&D projects. 
If the net externalities are negative $(\delta(k)<0)$, then it would be optimal to reduce the equilibrium number of firms investing in projects $\left(\alpha_{k}^{o}, \alpha_{k}\right)$ from $k$ to $k-1$. If the externalities are positive then the number of firms should be increased in the interval $\left(\alpha_{k}, \alpha_{k}^{o}\right)$.

From the perspective of a fixed project $j$, the question of whether the amount of duplication is optimal or not is essentially equivalent to the question whether the free entry in an industry with fixed costs is optimal or not. Here, the question is of an entry in a 'potential' industry, fixed costs are the cost of developing this specific project $C(j)$, and the number of firms that can enter is limited by the number of firms which are active in the pre-innovation market. Keeping in mind the upper bound on the number of firms imposed by $N$, the results derived in Mankiw and Whinston (1986) apply in this setting as well. For the homogeneous product market and ignoring the integer constraint, Mankiw and Whinston find that the free-entry equilibrium number of firms is not less than the socially optimal number of firms (i.e., there is no underinvestment in duplication in our terminology), and furthermore if the equilibrium price is above the marginal costs, then the equilibrium number of firms is strictly greater than the optimal number (i.e. there is overinvestment in duplication). ${ }^{13}$ That is, Mankiw and Whinston identify conditions under which an industry equilibrium would tend toward excessive entry. In the context of the present model, this implies that there should be a tendency toward overinvestment in duplication of $\mathrm{R} \& \mathrm{D}$ projects. Taking into account the integer constraint weakens this result somewhat - Mankiw and Whinston establish that the free-entry equilibrium number of firms is not lower than the optimal number of firms less one. ${ }^{14}$ In the notation of this article, that would be $n^{*}(j) \geq n^{o}(j)-1$ for appropriate project $j$. This suggests that even though there might be underinvestment in the duplication of $\mathrm{R} \& \mathrm{D}$ projects, it will be bounded from below.

\footnotetext{
${ }^{13}$ Proposition 1 in Mankiw and Whinston (1986).

${ }^{14}$ Proposition 2 in Mankiw and Whinston (1986).
} 


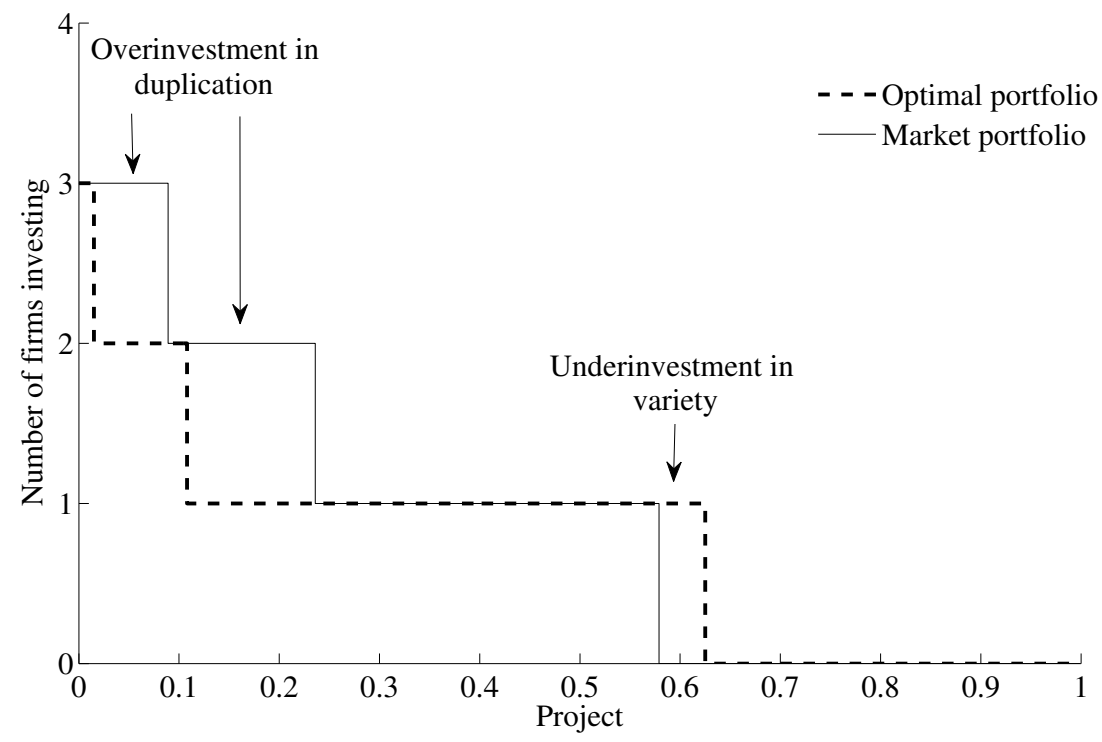

Figure 4: Optimal and market portfolios of research projects.

\section{Extensions and robustness}

This section relaxes several assumptions made in the model. For simplicity, in all following subsections except the first one, I will assume that there are only two firms in the market.

\section{Non-drastic innovations}

The assumption that innovation is drastic significantly simplifies the analysis, as it allows us to ignore all firms which have failed to innovate whenever at least one firm has innovated. However, there are many innovations which are incremental and which give only a slight advantage to the innovating firm over its rivals. This section relaxes Assumption 2 and provides a more general characterization of the market equilibrium portfolio.

First observe that Proposition 1 does not rely on Assumption 2. Hence, an equilibrium of the investment game exists and except in trivial cases an infinite number of equilibria exists. However, the equilibrium market portfolio is unique and any investment plan that generates the equilibrium market portfolio is itself an equilibrium of the investment game. The next result characterizes the equilibrium market portfolio without Assumption 2.

Proposition 2a (Characterization of equilibrium portfolio).

Suppose that Assumption 1 holds. Denote with $m$ the maximum number of firms investing 
in any project:

$$
\begin{gathered}
m=\max _{\{1, \ldots, N\}} n \\
\text { s.t. } R(n, N)-r(n-1, N)-C(0)>0
\end{gathered}
$$

and with $\alpha_{k}$ for $k \in\{1,2, \ldots, m\}$ the most expensive project in which $k$ firms can profitably invest. That is:

$$
\begin{gathered}
R(1, N)-r(0, N)-C\left(\alpha_{1}\right)= \\
R(2, N)-r(1, N)-C\left(\alpha_{2}\right)= \\
\vdots \\
R(m, N)-r(m-1, N)-C\left(\alpha_{m}\right)=0 .
\end{gathered}
$$

Let $\alpha_{m+1}=0$ and $\alpha_{0}=1$. Then the PSE portfolio $n^{*}(j)$ is given by

$$
n^{*}(j)=k \quad \text { if } \quad j \in\left[\alpha_{k+1}, \alpha_{k}\right) .
$$

The basic form of the equilibrium portfolio is the same as in the case with the drastic innovation - it is still a step function with a declining number of firms investing as projects become more expensive. There are two differences however. First, the payoffs with the innovation $R(\cdot, N)$ are now functions of $N$, because the firms without the innovation can put competitive pressure on the firms with the innovation. Second, firms without the innovation can now obtain positive profits, which decreases the incentive to duplicate research.

As a consequence, the comparative statics results become ambiguous if Assumption 2 does not hold. Consider a merger, so that the number of firms in the industry is reduced from $N$ to $N-1$. If Assumption 2 holds, then Proposition 3 holds and the merger leads to a decrease in the variety of projects undertaken. If Assumption 2 does not hold, the variety of projects undertaken will (weakly) decrease if and only if

$$
r(0, N-1)-r(0, N) \geq R(1, N-1)-R(1, N),
$$


or, in words, only if the merger increases profits without the innovation more than it does for the single innovator. An analogous condition is required for any other $n$-firm frontier as well as for the changes in the intensity of competition among firms.

Figure 5 illustrates the Cournot duopoly example from the appendix A.10 with drastic and with non-drastic innovation and shows that the essential structure of the model does not depend on Assumption 2.

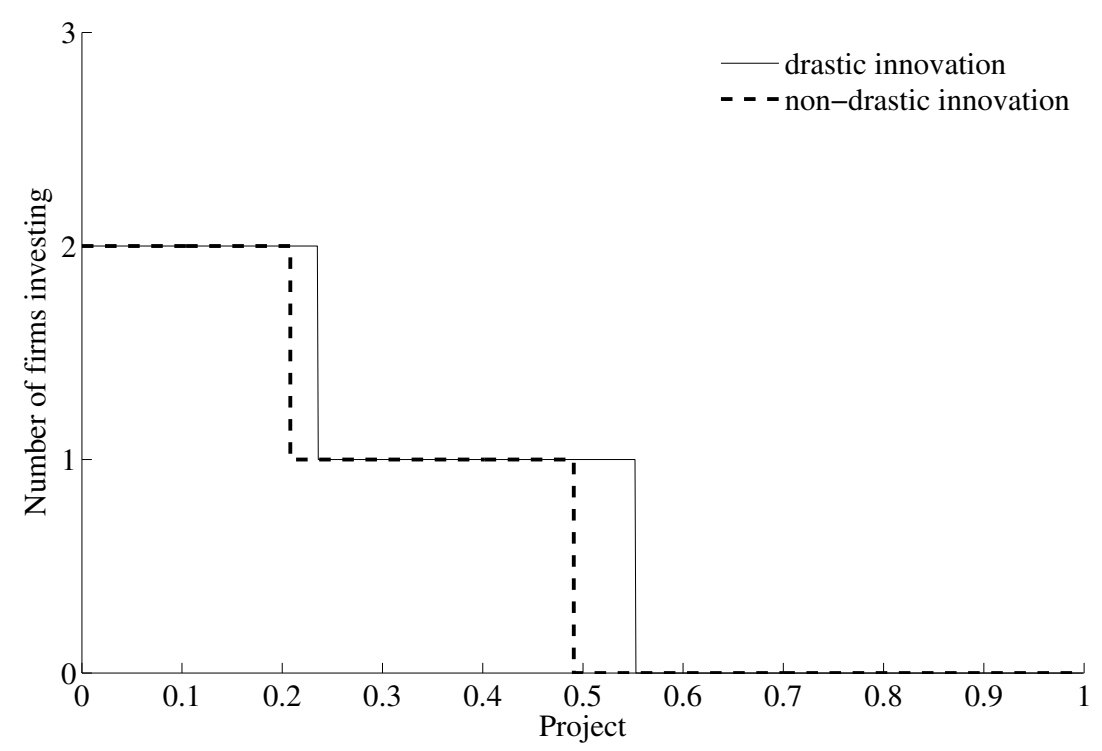

Figure 5: Drastic versus non-drastic innovation.

\section{Asymmetric firms}

Suppose that two firms are producing homogeneous goods with different technologies, so that one firm has lower marginal costs of production than the other. Call the more efficient firm the leader and denote its marginal production cost with $\bar{c}_{\text {lead }}$. Call the less efficient firm the laggard and denote its marginal production cost with $\bar{c}_{\text {lag }}$. Suppose that the firms are symmetric in all other aspects and furthermore suppose that firms can invest in the development of a new production technology which would lower the production costs of whichever firm develops it to $\underline{c}$, such that $\bar{c}_{l a g}>\bar{c}_{\text {lead }}>\underline{c}$. Suppose that Assumptions 1 and 2 hold.

First observe that if neither firm develops the innovation, firms will continue competing with the old technology and the leader's profits $r_{\text {lead }}(0,2)$ will be greater than 
the laggard's profits $r_{l a g}(0,2)$. However, as the innovation is drastic, the profits postinnovation will be the same for both firms $R_{\text {lead }}(1)=R_{\text {lag }}(1)$ and $R_{\text {lead }}(2)=R_{\text {lag }}(2)$. To simplify exposition, assume $C(0)<R(2)$. Analogously to before, denote the $k$-firm frontiers as

$$
\begin{aligned}
\alpha_{1, \text { lag }} & =C^{-1}\left(R(1)-r_{\text {lag }}(0,2)\right), \\
\alpha_{1, \text { lead }} & =C^{-1}\left(R(1)-r_{\text {lead }}(0,2)\right), \\
\alpha_{2} & =C^{-1}(R(2)),
\end{aligned}
$$

where $\alpha_{1, \text { lag }}$ is the most expensive project in which the laggard would invest and $\alpha_{1, \text { lead }}$ is the most expensive project in which the leader would invest. It is straightforward to see that $\alpha_{2} \leq \alpha_{1, \text { lead }}<\alpha_{1, \text { lag }}$. In equilibrium, both firms will invest in the interval $\left[0, \alpha_{2}\right)$, for any project in the interval $\left[\alpha_{2}, \alpha_{1, \text { lead }}\right.$ ) either the leader or the laggard will invest (but only one will), and only the laggard will invest in the interval $\left[\alpha_{1, \text { lead }}, \alpha_{1, \text { lag }}\right)$, whereas no firm will invest in the interval $\left[\alpha_{1, \text { lag }}, 1\right)$. Hence this model predicts that the laggard firms will be more likely to invest in the most expensive projects. Furthermore, if one is willing to assume that where both firms can invest they do so symmetrically, the laggard will be more likely to develop drastic innovations. This prediction is consistent with the results in Akcigit and Kerr (2010), who find that smaller firms tend to have higher R\&D expenses per employee and more patents per employee than larger firms.

Figure 6 illustrates the equilibrium market portfolio of research projects, using the Cournot duopoly from the appendix A.10.

\section{Innovations as strategic complements}

Consider a case with two firms in the industry and relax Assumption 1. Assumption 1 will not hold if innovations are sufficiently strong complements, for example in the case of research spillovers. If Assumption 1 does not hold then it must be true that:

$$
R(2,2)-r(1,2)>R(1,2)-r(0,2)
$$




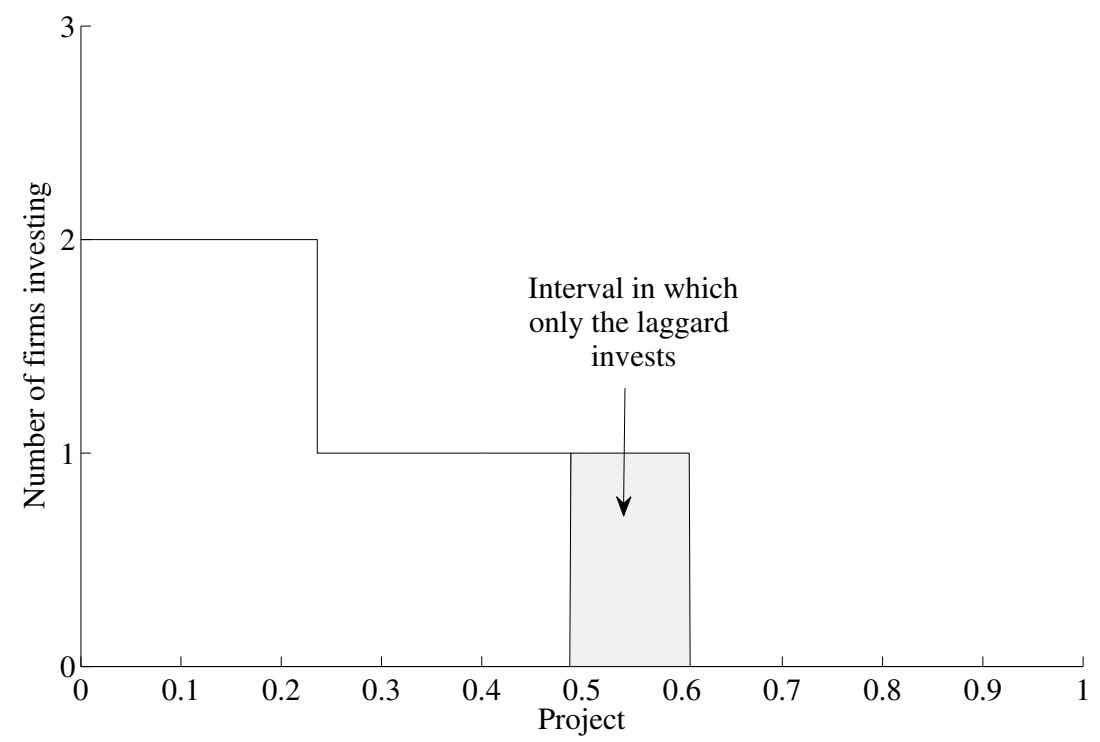

Figure 6: Asymmetric firms.

Assumption 2 is immaterial for the following discussion and it is not assumed to hold. Analogous to the use of $k$-firm frontiers before, let:

$$
\begin{aligned}
& \alpha_{1}=C^{-1}(R(1,2)-r(0,2)), \\
& \alpha_{2}=C^{-1}(R(2,2)-r(1,2)),
\end{aligned}
$$

where $C^{-1}(\cdot)$ is the inverse of the function $C(\cdot)$. As $C(\cdot)$ is a strictly increasing function, we have $\alpha_{2}>\alpha_{1}$. This introduces ambiguity in the number of firms that will, in equilibrium, invest in the interval $\left[\alpha_{1}, \alpha_{2}\right)$. A single firm cannot profitably invest in any project in this interval, but two firms can. Hence, in equilibrium, it must hold that in any project in this interval, either no firm invests or both do. In the interval $\left[0, \alpha_{1}\right)$ both firms will invest, whereas in the interval $\left[\alpha_{2}, 1\right)$ neither firm will invest. If Assumption 1 does not hold, there will be an infinity of equilibrium market portfolios. In this sense, Assumption 1 is essential for the model. Figure 7 illustrates the equilibrium market portfolio of research projects. 


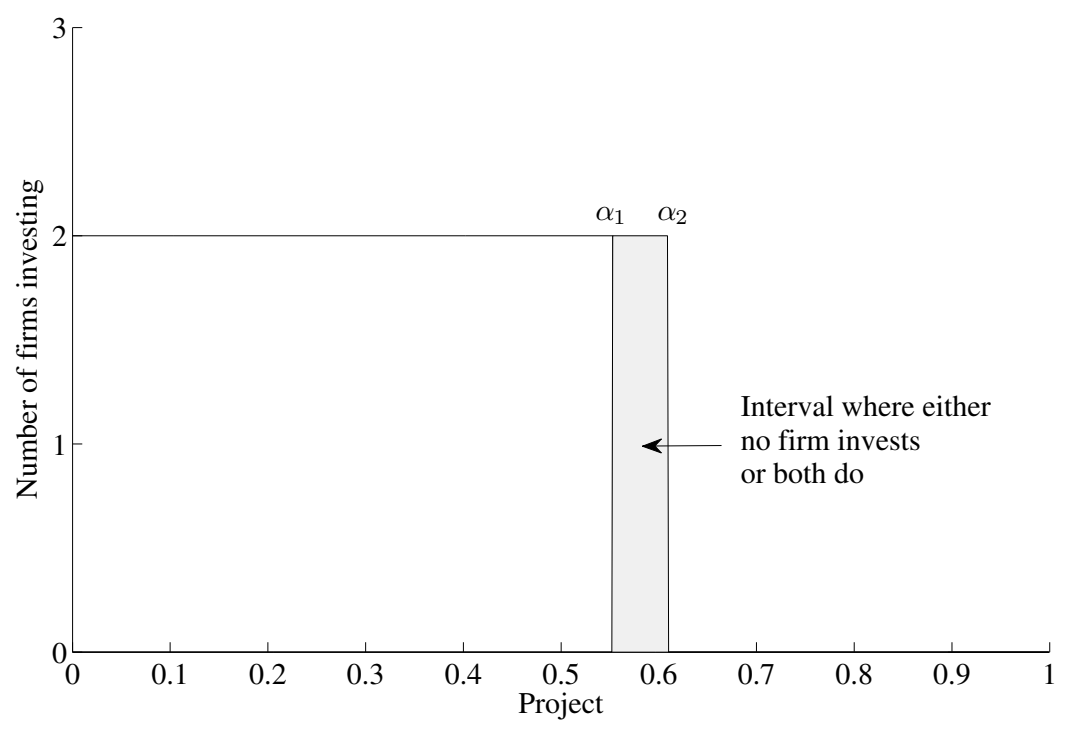

Figure 7: Violating Assumption 1.

\section{Conclusion}

This article studies how the market structure, that is the number of firms competing on the market and the nature of competition among them, influences the choice of research projects undertaken. The main object of analysis is the R\&D portfolio, an object that captures both the variety of research projects undertaken, as well as the amount of duplicative research.

It is shown that, even though the effect of an increase in competition on the total level of investment in innovation is ambiguous, the increase in competition increases the variety of approaches to innovation and increases the probability that an innovation is discovered. The policy recommendation drawn from this conclusion is that competition authorities should take into account this negative effect on the investment in innovation when reviewing merger cases.

Comparing the equilibrium market portfolio with the optimal equilibrium portfolio, it is shown that the market will tend to underinvest in drastic innovation. This underinvestment will be more severe the higher the potential benefit from innovation and the lower the overall intensity of competition in the industry. This suggests that R\&D subsidies should be targeted at high cost and high potential benefit projects (so-called blue sky projects) - especially in the industries with few firms and low intensity of competition. 
This article presents an innovation model where firms choose R\&D projects in which to invest. In this model, the variety of approaches to innovation as well as the duplication of $R \& D$ projects can be explicitly analyzed. This opens up at least two avenues for future research. First, a choice-of-R\&D-projects model could be embedded into a growth framework, which could be used to analyze how different market structure and government policies could influence variety and duplication of R\&D projects and through it long-term economic growth. Second, as eloquently argued in Segal and Whinston (2007), competition policy needs to focus more on the long-term effects such policy has on innovation in any given industry. The present model could be extended into a dynamic framework, so that questions of variety and duplication of R\&D projects could be analyzed in a dynamic setting.

\section{A Appendix}

\section{A.1 Proof of Proposition 1}

I prove each of the three statements contained in Proposition 1 in turn.

Lemma 1 (Existence). An equilibrium in pure actions always exists.

I provide a constructive proof of Lemma 1 in three steps. Step 1 constructs the candidate equilibrium investment plan $I^{*}$. Step 2 proves that no firm can increase its expected profits by making additional investments. Step 3 proves that no firm can increase its expected profits by reducing investments. Finally, notice that any deviation from the investment plan $I^{*}$ can be written as a collection of investments and divestments and by Steps 2 and 3, each such investment and divestment decreases expected profits and hence any such collection must decrease expected profits. Thus, no firm can profitably deviate from the investment plan $I^{*}$ and then, by definition, $I^{*}$ is an equilibrium.

Step 1. Constructing the candidate equilibrium.

Given a game, define $m$ such that

$$
m=\max _{\{1, \ldots, N\}} n
$$




$$
\text { s.t. } R(n, N)-r(n-1, N)-C(0)>0
$$

As by assumption $R(1, N)-r(0, N)-C(0)>0$, a solution to this maximization problem always exists.

Next, calculate each $\alpha_{1}, \alpha_{2}, \ldots, \alpha_{m}$ such that the following condition holds:

$$
\begin{gathered}
R(1, N)-r(0, N)-C\left(\alpha_{1}\right)= \\
R(2, N)-r(1, N)-C\left(\alpha_{2}\right)= \\
R(3, N)-r(2, N)-C\left(\alpha_{3}\right)= \\
\vdots \\
R(m, N)-r(m-1, N)-C\left(\alpha_{m}\right)=0 .
\end{gathered}
$$

By construction it holds $R(m, N)-r(m-1, N)-C(0)>0$ and by Assumption 1 the reward of innovation are non-increasing, so the inequality holds for all $k<m$. As costs of innovation approach infinity as $j \rightarrow 1$, values $\alpha_{1}, \alpha_{2}, \ldots, \alpha_{m}$ always exist by the Intermediate Value Theorem. Furthermore, as $C(j)$ is increasing and by applying Assumption 1 it is easy to see that $\alpha_{1} \geq \alpha_{2} \geq \cdots \geq \alpha_{m}$.

Observe that $N \geq m$. For each $i \in\{1, \ldots, m\}$, let $I_{i}^{*}=\left[0, \alpha_{i}\right)$. For each $i \in$ $\{m+1, \ldots, N\}$ let $I_{i}^{*}=\emptyset$. I will demonstrate that $I^{*}$ is an equilibrium.

Step 2. Suppose that $I^{*}$ is constructed as above. Then no firm can increase its expected profits by making additional investments.

Proof. First observe that as $\forall j \in\left(\alpha_{1}, 1\right)$, by construction $R(1, N)-r(0, N)-C(j)<0$, no firm has an incentive to invest beyond the technology frontier. I will consider separately the firms which in $I^{*}$ have some investment and those firms which do not.

First, fix a firm $i^{\prime} \in\{1, \ldots, m\}$ and take any feasible investment interval $L \subseteq\left[\alpha_{i^{\prime}}, \alpha_{1}\right)$. It must be that $\min (L) \in\left[\alpha_{k}, \alpha_{k-1}\right)^{15}$ for some $k \leq i^{\prime}$ and $k \geq 2$ and $\sup (L) \in\left(\alpha_{k^{\prime}}, \alpha_{k^{\prime}-1}\right]$ for some $k^{\prime} \leq i^{\prime}$ and $k^{\prime} \geq 2$, with $k^{\prime} \leq k$.

First consider the case where $k^{\prime}=k$. Then $L \subseteq\left[\alpha_{k}, \alpha_{k-1}\right)$. Observe that $R(k, N)-$ $r(k-1, N)-C\left(\alpha_{k}\right)=0$ and $n\left(j, I^{*}\right)=k-1$ for all $j \in\left[\alpha_{k}, \alpha_{k-1}\right)$ by construction. As

\footnotetext{
${ }^{15}$ If $\alpha_{k}=\alpha_{k-1}$, let $L=\left\{\alpha_{k}\right\}$ and $\min (L)=\alpha_{k}$.
} 
$C(\cdot)$ is assumed to be strictly increasing, then $R(k, N)-r(k-1, N)-C(j)<0$ for all $j \in(\min (L), \sup (L))$. Hence,

$$
-\int_{L} C(j) d j+\int_{L} R(k, N) d j-\int_{L} r(k-1, N) d j<0
$$

and the firm $i^{\prime}$ has no incentive to invest in the interval $L$.

Next consider the case where $k^{\prime}<k$. Then we can write $L=\left[\min (L), \alpha_{k-1}\right) \cup$ $\left[\alpha_{k-1}, \alpha_{k-2}\right) \cup \cdots \cup\left[\alpha_{k^{\prime}}, \sup (L)\right)$. Denote these subintervals as $L^{k-1}, L^{k-2}, \ldots, L^{k^{\prime}-1}$. Observe that by construction, the following statements hold:

$$
\begin{array}{rr}
R(k, N)-r(k-1, N)-C\left(\alpha_{k}\right)=0 \text { and } n\left(j, I^{*}\right)=k-1 & \text { for all } j \in L^{k-1} \\
R(k-1, N)-r(k-2, N)-C\left(\alpha_{k-1}\right)=0 \text { and } n\left(j, I^{*}\right)=k-2 & \text { for all } j \in L^{k-2} \\
\vdots & \\
R\left(k^{\prime}, N\right)-r\left(k^{\prime}-1, N\right)-C\left(\alpha_{k^{\prime}}\right)=0 \text { and } n\left(j, I^{*}\right)=k^{\prime}-1 \quad \text { for all } j \in L^{k^{\prime}-1}
\end{array}
$$

As $C(\cdot)$ is assumed to be strictly increasing, the following statements hold:

$$
\begin{aligned}
& R(k, N)-r(k-1, N)-C(j)<0 \quad \text { for all } j \in L^{k-1} \\
& R(k-1, N)-r(k-2, N)-C(j)<0 \quad \text { for all } j \in L^{k-2} \\
& R\left(k^{\prime}, N\right)-r\left(k^{\prime}-1, N\right)-C(j)<0 \quad \text { for all } j \in L^{k^{\prime}-1}
\end{aligned}
$$

But then it holds

$$
\begin{aligned}
& \int_{L} R\left(n\left(j, I^{*}\right)+1, N\right)-r\left(n\left(j, I^{*}\right), N\right)-C(j) d j= \\
& =\left(\int_{L^{k-1}} R(k, N)-r(k-1, N)-C(j) d j\right)+\left(\int_{L^{k-2}} R(k-1, N)-r(k-2, N)-C(j) d j\right)+ \\
& \cdots+\left(\int_{L^{k^{\prime}-1}} R\left(k^{\prime}, N\right)-r\left(k^{\prime}-1, N\right)-C(j) d j\right)<0
\end{aligned}
$$

and the firm $i^{\prime}$ has no incentive to invest in the interval $L$. 
Next, fix a firm $i^{\prime} \in\{m+1, \ldots, N\}$ and take any feasible investment interval $L \subseteq$ $\left[0, \alpha_{1}\right)$. Observe that we can write $L$ as a union of two sets, $L=L^{\prime} \cup L^{\prime \prime}$ where $L^{\prime} \subseteq\left[0, \alpha_{m}\right)$ and $L^{\prime \prime} \subseteq\left[\alpha_{m}, \alpha_{1}\right)$. By the same argument as above, it holds that any investment in the set $L^{\prime \prime}$ cannot be profitable. Consider now an investment in the set $L^{\prime}$. By construction, $m$ is the maximum number of firms that can profitably invest in the project $j=0$. As $C(j)$ is strictly increasing it is also the maximum number of firms that can invest in any project. By construction, there are $m$ firms investing in all projects in $\left[0, \alpha_{m}\right)$ and as a result the firm $i^{\prime}$ cannot profitably invest in the set $L^{\prime}$. Thus, the investment in the set $L$ cannot be profitable.

Step 3. Suppose that $I^{*}$ is constructed as above. Then no firm can increase its expected profits by decreasing investments.

Proof. First observe that all firms $i>m$ have zero investments by construction and hence cannot decrease their investments. Fix a firm $i^{\prime} \in\{1, \ldots, m\}$ and take any feasible investment interval $L \subseteq\left[0, \alpha_{i^{\prime}}\right)$. Consider a disinvestment from the set $L$. It must be that $\min (L) \in\left[\alpha_{k}, \alpha_{k-1}\right)$ for some $k-1 \geq i^{\prime}$ with $k \leq m+1$ and $\alpha_{m+1}=0$ and $\sup (L) \in\left(\alpha_{k^{\prime}}, \alpha_{k^{\prime}-1}\right]$ for some $k^{\prime}-1 \geq i^{\prime}$ and $k^{\prime} \leq k$.

Consider the case where $k^{\prime}=k$. Then $L \subseteq\left[\alpha_{k}, \alpha_{k-1}\right)$. Observe that $R(k-1, N)-$ $r(k-2, N)-C(j)>0$ and $n\left(j, I^{*}\right)=k-1$ for all $j \in\left(\alpha_{k}, \alpha_{k-1}\right)$ by construction. Hence,

$$
\int_{L} R(k-1, N)-r(k-2, N)-C(j) d j>0 .
$$

and the firm $i^{\prime}$ has no incentive to divest from the interval $L$.

Next consider the case where $k^{\prime}<k$. Then we can write $L=\left[\min (L), \alpha_{k-1}\right) \cup$ $\left[\alpha_{k-1}, \alpha_{k-2}\right) \cup \cdots \cup\left[\alpha_{k^{\prime}}, \sup (L)\right)$. Denote these subintervals as $L^{k-1}, L^{k-2}, \ldots, L^{k^{\prime}-1}$. 
Observe that by construction, the following statements hold:

$$
\begin{array}{rr}
R(k-1, N)-r(k-2, N)-C(j)>0 \text { and } n\left(j, I^{*}\right)=k-1 & \text { for all } j \in L^{k-1} \\
R(k-2, N)-r(k-3, N)-C(j)>0 \text { and } n\left(j, I^{*}\right)=k-2 & \text { for all } j \in L^{k-2} \\
\vdots & \\
R\left(k^{\prime}-1, N\right)-r\left(k^{\prime}-2, N\right)-C(j)>0 \text { and } n\left(j, I^{*}\right)=k^{\prime}-1 & \text { for all } j \in L^{k^{\prime}-1}
\end{array}
$$

But then it holds

$$
\begin{aligned}
& \int_{L^{\prime \prime}} R\left(n\left(j, I^{*}\right), N\right)-r\left(n\left(j, I^{*}\right)-1, N\right)-C(j) d j= \\
& \begin{aligned}
\int_{L^{k-1}} R(k-1, N)-r(k-2, N) & -C(j) d j+\int_{L^{k-2}} R(k-2, N)-r(k-3, N)-C(j) d j+ \\
& +\cdots+\int_{L^{k^{\prime}-1}} R\left(k^{\prime}-1, N\right)-r\left(k^{\prime}-2, N\right)-C(j) d j>0
\end{aligned}
\end{aligned}
$$

and the firm $i^{\prime}$ has no incentive to divest from the interval $L$.

Thus no firm can increase its expected profits by divesting from any feasible interval $L$.

Lemma 2. If $I^{*}$ is an equilibrium and $0<n\left(j, I^{*}\right)<N$ for some $j \in[0,1)$, then infinitely many equilibria exist.

Proof. Let $I^{*}$ be an equilibrium and fix some $j \in[0,1)$ such that $0<n\left(j, I^{*}\right)<N$. Then there exist firms $i$ and $i^{\prime}$ such that $j \in I_{i}$ and $j \notin I_{i^{\prime}}$. Then there must exist some $\epsilon>0$ such that $[j, j+\epsilon) \cap I_{i}=[j, j+\epsilon)$ and $[j, j+\epsilon) \cap I_{i^{\prime}}=\emptyset$.

Consider an investment plan $\hat{I}$ such that $\hat{I}_{i^{\prime \prime}}=I_{i^{\prime \prime}}^{*}$, for all $i^{\prime \prime} \neq i, i^{\prime}$. For $i$ and $i^{\prime}$ let $\hat{I}_{i}=I_{i}^{*} \backslash[j, j+\epsilon)$ and $\hat{I}_{i^{\prime}}=I_{i^{\prime}}^{*} \cup[j, j+\epsilon)$. In words, only transfer the ownership of investment in projects $[j, j+\epsilon)$ from firm $i$ to firm $i^{\prime}$ and leave everything else unchanged. I will demonstrate that $\hat{I}$ is also an equilibrium and hence, because there is an infinite number of ways to choose $\epsilon$, there exists an infinity of equilibria.

Suppose that $\hat{I}$ is not an equilibrium. Then, there exists a firm that can profitably change its investment plan. This means that there exists an interval $L \subset[0,1)$ and a 
firm $i^{l}$ such that firm can increase its expected profits by either investing in the interval $L$ or divesting from the interval $L$. Consider first those firms $i^{\prime \prime} \neq i, i^{\prime}$. By construction $n\left(j, I^{*}\right)=n(j, \hat{I})$ for all $j \in[0,1)$. From Equation 1, it is clear that strategic effects only influence the expected profit through $n(j, I)$. Thus, if a firm can profitably deviate from $\hat{I}$ it can also profitably deviate from $I^{*}$.

Next, consider firms $i$ and $i^{\prime}$. As their investment plans are unchanged in the set $[0, j) \cup[j+\epsilon, 1)$ by an argument identical to the one above, if they could profitably deviate in this set from $\hat{I}$, they could also profitably deviate from $I^{*}$. Now consider the set $[j, j+\epsilon)$. Firm $i^{\prime}$ can deviate in this set only by not investing. Suppose that there exists an interval $L^{\prime} \subseteq[j, j+\epsilon)$, such that not investing in this set increases the expected profits of firm $i^{\prime}$. Then it must be the case that

$$
\int_{L^{\prime}} R(n(j, \hat{I}), N)-r(n(j, \hat{I})-1, N)-C(j) d j<0
$$

But in this case, firm $i$ could profitably deviate from $I^{*}$ by not investing in the interval $L^{\prime}$. Next, firm $i$ can deviate in the set $[j, j+\epsilon)$ only by investing. Suppose that there exists an interval $L^{\prime} \subseteq[j, j+\epsilon)$, such that investing in this set increases the expected profits of firm $i$. Then it must be the case that

$$
\int_{L^{\prime}} R(n(j, \hat{I})+1, N)-r(n(j, \hat{I}), N)-C(j) d j>0
$$

But in this case, firm $i^{\prime}$ could profitably deviate from $I^{*}$ by investing in the interval $L^{\prime}$.

Thus, in each case, a profitable deviation from $\hat{I}$ implies a profitable deviation from $I^{*}$ which contradicts the initial assumption that $I^{*}$ is an equilibrium.

Lemma 3. If there are multiple equilibria they all result in the same market portfolio of investment in innovation. That is, if $I_{1}^{*}$ and $I_{2}^{*}$ are equilibrium investment plans, then $n\left(j, I_{1}^{*}\right)=n\left(j, I_{2}^{*}\right)$ for all $j \in[0,1)$. If $I_{1}^{*}$ is an equilibrium then any investment plan $I_{3}^{*}$ such that $n\left(j, I_{1}^{*}\right)=n\left(j, I_{3}^{*}\right)$ for all $j \in[0,1)$ is also an equilibrium.

I prove this Lemma in two steps, each proving one part of the Lemma.

Step 1. If there are multiple equilibria they all result in the same market portfolio of 
investment in innovation. That is, if $I_{1}^{*}$ and $I_{2}^{*}$ are equilibrium investment plans, then $n\left(j, I_{1}^{*}\right)=n\left(j, I_{2}^{*}\right)$ for all $j \in[0,1)$.

Proof. Suppose not. Then, there exists a point $j \in[0,1)$ such that $n\left(j, I_{1}^{*}\right) \neq n\left(j, I_{2}^{*}\right)$. Suppose, without loss of generality, that $n\left(j, I_{1}^{*}\right)>n\left(j, I_{2}^{*}\right)$. Fix a firm $i$ and a point $\epsilon>0$ such that it holds $[j, j+\epsilon) \cap I_{1, i}^{*}=[j, j+\epsilon)$ and $[j, j+\epsilon) \cap I_{2, i}^{*}=\emptyset$ and $n\left(l, I_{1}^{*}\right)=$ const , $n\left(l, I_{2}^{*}\right)=$ const, $\forall l \in[j, j+\epsilon)$. Such a firm and a point always exist.

(1) Suppose $R\left(n\left(j, I_{1}^{*}\right), N\right)-r\left(n\left(j, I_{1}^{*}\right)-1, N\right) \geq C(j+\epsilon)$. As $C(\cdot)$ is increasing it holds $R\left(n\left(j, I_{1}^{*}\right), N\right)-r\left(n\left(j, I_{1}^{*}\right)-1, N\right)>C(l)$ for all $l \in[j, j+\epsilon)$. By Assumption 1 it holds $R\left(n\left(j, I_{2}^{*}\right)+1, N\right)-r\left(n\left(j, I_{2}^{*}\right), N\right)>C(l)$ for all $l \in[j, j+\epsilon)$. Then it holds

$$
\int_{j}^{j+\epsilon} R\left(n\left(l, I_{2}^{*}\right)+1, N\right)-r\left(n\left(l, I_{2}^{*}\right), N\right)-C(l) d l>0 .
$$

Then $I_{2}^{*}$ cannot be an equilibrium as firm $i$ could increase its expected profits by investing in the interval $[j, j+\epsilon)$.

(2) Suppose $R\left(n\left(j, I_{1}^{*}\right), N\right)-r\left(n\left(j, I_{1}^{*}\right)-1, N\right)<C(j+\epsilon)$. Then there exists an $\epsilon^{\prime}>0$ such that $R\left(n\left(j, I_{1}^{*}\right), N\right)-r\left(n\left(j, I_{1}^{*}\right)-1, N\right)<C(l)$ for all $l \in\left[j+\epsilon-\epsilon^{\prime}, j+\epsilon\right)$. Then it holds

$$
\int_{j+\epsilon-\epsilon^{\prime}}^{j+\epsilon} R\left(n\left(l, I_{1}^{*}\right), N\right)-r\left(n\left(l, I_{1}^{*}\right)-1, N\right)-C(l) d l<0 .
$$

Then $I_{1}^{*}$ cannot be an equilibrium as firm $i$ could increase its expected profits by not investing in the interval $\left[j+\epsilon-\epsilon^{\prime}, j+\epsilon\right)$.

Step 2. If $I_{1}^{*}$ is an equilibrium then any investment plan $I_{3}^{*}$ such that $n\left(j, I_{1}^{*}\right)=n\left(j, I_{3}^{*}\right)$ for all $j \in[0,1)$ is also an equilibrium.

Proof. Suppose not. Then in the investment plan $I_{3}^{*}$ exists a firm $i$ and an interval $L$ such that firm $i$ would be better off by either investing in the interval $L$ or by divesting from interval $L$.

(1) Suppose that the firm $i$ can profitably invest in the interval $L$. Then there exists $L^{\prime} \subseteq L$ such that $R\left(n\left(j, I_{3}^{*}\right)+1\right)-r\left(n\left(j, I_{3}^{*}\right), N\right)>C(l)$ for all $l \in L^{\prime}$. But then there exists a firm $i^{\prime \prime}$ and a set $L^{\prime \prime} \subseteq L^{\prime}$ such that $L^{\prime \prime} \cap I_{1, i^{\prime \prime}}^{*}=\emptyset$. Then $I_{1}^{*}$ cannot be an equilibrium as the firm $i^{\prime \prime}$ could profitably deviate by investing in the interval $L^{\prime \prime}$. 
(2) Suppose that the firm $i$ can profitably divest from the interval $L$. Then there exists $L^{\prime} \subseteq L$ such that $R\left(n\left(j, I_{3}^{*}\right), N\right)-r\left(n\left(j, I_{3}^{*}-1\right), N\right)<C(l)$ for all $l \in L^{\prime}$. But then there exists a firm $i^{\prime \prime}$ and a set $L^{\prime \prime} \subseteq L^{\prime}$ such that $L^{\prime \prime} \cap I_{1, i^{\prime \prime}}^{*}=L^{\prime \prime}$. Then $I_{1}^{*}$ cannot be an equilibrium as the firm $i^{\prime \prime}$ could profitably deviate by divesting from the interval $L^{\prime \prime}$.

\section{A.2 Proof of Proposition 2}

Proof. Observe that by Assumption 2, for all $n \geq 1$ we have $r(n, N)=0$. Let $I^{*}$ be the equilibrium constructed in the proof of Lemma 1. If $n^{*}(j)$ as constructed in Proposition 2 is equal to $n\left(j, I^{*}\right)$ for all $j \in[0,1)$, then by statement 3 in Proposition 1 it characterizes the equilibrium market portfolio of research projects.

I here show that $n^{*}(j)=n\left(j, I^{*}\right)$. First, as noted in the proof of Lemma 1, observe that $\alpha_{1} \geq \alpha_{2} \geq \cdots \geq \alpha_{m}$. First suppose that $j \in\left[\alpha_{1}, 1\right)$ Then it must be that $j \geq \alpha_{k}$ for all $k \in\{1, \ldots, m\}$. Hence $n^{*}(j)=0$. By construction, $n\left(l, I^{*}\right)=0$ for all $l \in\left[\alpha_{1}, 1\right)$. Next, suppose that $j \in\left[0, \alpha_{1}\right)$. Then

$$
\begin{gathered}
n^{*}(j)=\max _{1, \ldots, m} k \\
\text { s.t. } j<\alpha_{k}
\end{gathered}
$$

Let $\hat{k}=n^{*}(j)$. It holds that $j<\alpha_{\hat{k}} \leq \alpha_{\hat{k}-1} \leq \cdots \leq \alpha_{1}$. By construction, each firm $i$ such that $i \in\{1, \ldots, \hat{k}\}$ invests in $j$. Hence, $n\left(j, I^{*}\right)=\hat{k}$.

\section{A.3 Proof of Proposition 3}

I will prove each statement in the proposition in turn. Let the number of firms in the pre-innovation market increase from $N$ to $N^{\prime}$. Denote the maximum number of firms investing in two cases as $m$ and $m^{\prime}$ and the k-firm frontiers as $\alpha_{k}$ and $\alpha_{k}^{\prime}$.

Lemma 4. In equilibrium, the variety of projects developed and the probability of developing an innovation weakly increases, that is $\alpha_{1} \leq \alpha_{1}^{\prime}$.

Proof. By Proposition 2 the variety of projects developed in the two equilibria is equal to the sets $\left[0, \alpha_{1}\right)$ and $\left[0, \alpha_{1}^{\prime}\right)$ and the probability of successfully developing an innovation 
is equal to $\alpha_{1}$ and $\alpha_{1}^{\prime}$. Thus we need to show that $\alpha_{1} \leq \alpha_{1}^{\prime}$. By Proposition 2 we have $R(1)-r(0, N)=C\left(\alpha_{1}\right)$ and $R(1)-r\left(0, N^{\prime}\right)=C\left(\alpha_{1}^{\prime}\right)$. By assumption 3 we have $r\left(n-1, N^{\prime}\right) \leq r(n-1, N)$ hence $C\left(\alpha_{1}^{\prime}\right) \geq C\left(\alpha_{1}\right)$. As $C(j)$ is assumed to be increasing this implies $\alpha_{1}^{\prime} \geq \alpha_{1}$.

Lemma 5. The maximum number of firms investing also increases, that is $m \leq m^{\prime}$.

Proof. By Proposition 2 we have $m=\max _{\{1, \ldots, N\}} n$ such that $R(n)-r(n-1, N)-C(0)>$ 0 . Observe that $m \in\{1, \ldots, N\} \subseteq\left\{1, \ldots, N^{\prime}\right\}$. If $n=1$, by assumption 3 we have $R(n)-r\left(n-1, N^{\prime}\right)-C(0) \geq R(n)-r(n-1, N)-C(0)$. If $n>1$, by assumption 2 we have $R(n)-r\left(n-1, N^{\prime}\right)-C(0)=R(n)-r(n-1, N)-C(0)$. Hence $m$ is chosen from a subset from which $m^{\prime}$ is chosen and it satisfies a stricter condition. Thus $m^{\prime}$ cannot be lower than $m$.

Lemma 6. Apart from the increase in variety of projects developed and in the maximum number of firms investing, the equilibrium portfolio remains the same. That is, $n(j, I)=$ $n\left(j, I^{\prime}\right)$ for all $j \in[0,1) \backslash\left\{\left[0, \alpha_{m^{\prime}}^{\prime}\right] \cup\left[\alpha_{1}, \alpha_{1}^{\prime}\right]\right\}$.

Proof. Because $\alpha_{1}^{\prime} \geq \alpha_{1}$, we have $n(j, I)=n\left(j, I^{\prime}\right)=0$ for all $j \in\left[\alpha_{1}^{\prime}, 1\right)$. As $R(k)$ does not depend on $N$ or $N^{\prime}$, by Proposition 2 it follows that $\alpha_{k}=\alpha_{k}^{\prime}$ for all $2 \leq k \leq m$. Again by Proposition 2 it follows that $n(j, I)=n\left(j, I^{\prime}\right)$ for all $j \in\left(\alpha_{m^{\prime}}^{\prime}, \alpha_{1}\right)$.

\section{A.4 Proof of Proposition 4}

Proof. Suppose the intensity of competition increases from $(R, r)$ to $\left(R^{\prime}, r^{\prime}\right)$. Denote the respective equilibrium investment plans as $I$ and $I^{\prime}$. Then the following holds by direct application of Proposition 2:

$$
\begin{aligned}
& m^{\prime} \begin{cases}=m & \text { if } R^{\prime}(m, N)-C(0)>0 \\
<m & \text { otherwise }\end{cases} \\
& \alpha_{k}^{\prime}<\alpha_{k} \quad \forall k \in\left\{2, \ldots, m^{\prime}\right\} \\
& \alpha_{1}^{\prime}>\alpha_{1}
\end{aligned}
$$


and

$$
\begin{array}{rr}
n\left(j, I^{\prime}\right) \leq n(j, I) & \text { for all } j \in\left[0, \alpha_{1}\right) \\
n\left(j, I^{\prime}\right)>n(j, I) & \text { for all } j \in\left[\alpha_{1}, \alpha_{1}^{\prime}\right) \\
n\left(j, I^{\prime}\right)=n(j, I)=0 & \text { for all } j \in\left[\alpha_{1}^{\prime}, 1\right) .
\end{array}
$$

Because $\alpha_{1}^{\prime}>\alpha_{1}$ the variety of research projects undertaken and the probability of discovering an innovation increase. Because $\alpha_{k}^{\prime}<\alpha_{k} \quad \forall k \in\left\{2, \ldots, m^{\prime}\right\}$ there are some projects which are developed by fewer firms than with less intense competition. Hence the amount of duplication of research decreases.

\section{A.5 Proof of Proposition 5}

Proof. The portfolio given in Proposition 5 can always be constructed. I show that it is optimal. Suppose not. Then, there exists a project $j \in[0,1)$ such that investing either more or less than $n^{o}(j)$ marginally increases the expected welfare. There are two cases: (1) there exists a possibility to profitably increase investment in some project and (2) there exists a possibility to profitably decrease investment in some project.

(1) Suppose that there exists a possibility to profitably increase investment in some project $j$. Then there exists some $n$ such that $n^{0}(j)<n \leq N$ and

$$
W(n)-n C(j)>W\left(n^{0}(j)\right)-n^{0}(j) C(j)
$$

Then we can write

$$
\begin{gathered}
{\left[\sum_{k=n^{o}(j)+1}^{n} W(k)-W(k-1)-C(j)\right]+W\left(n^{0}(j)\right)-n^{0}(j) C(j)>W\left(n^{0}(j)\right)-n^{0}(j) C(j)} \\
\sum_{k=n^{o}(j)+1}^{n} W(k)-W(k-1)-C(j)>0 .
\end{gathered}
$$


Suppose $n^{o}(j)=m^{o}$. Then, $\forall k>n^{o}(j)$ it holds:

$$
(W(k)-W(k-1)-C(0))+(C(0)-C(j)) \leq 0
$$

the first bracketed expression is by construction not positive whereas the second is not positive because the function $C(\cdot)$ is increasing. A sum of non-positive elements cannot be positive. A contradiction.

Suppose now that $n^{o}(j)<m^{o}$. By construction it holds

$$
W\left(n^{0}(j)+1\right)-W\left(n^{0}(j)\right)-C\left(\alpha_{n^{0}(j)+1}^{o}\right)=0
$$

and for every $k>n^{0}(j)$ by assumption holds

$$
W(k)-W(k-1)-C\left(\alpha_{n^{0}(j)+1}^{o}\right) \leq 0
$$

By construction $j>\alpha_{n^{0}(j)+1}^{o}$, so that $C(j)>C\left(\alpha_{n^{0}(j)+1}^{o}\right)$. Plugging it into the expression above, it follows

$$
W(k)-W(k-1)-C(j) \leq 0 \quad \forall k>n^{0}(j) .
$$

Again, a sum of non-positive elements cannot be positive. A contradiction.

(2) Suppose that there exists a possibility to profitably decrease investment in some project $j$. Then there exists some $n$ such that $0 \leq n<n^{0}(j)$ and

$$
W(n)-n C(j)>W\left(n^{0}(j)\right)-n^{0}(j) C(j)
$$

Then we can write

$$
\begin{aligned}
W(n)-n C(j)>W(n)-n C(j)+\left[\sum_{k=n+1}^{n^{o}(j)} W(k)-W(k-1)-C(j)\right] \\
0>\sum_{k=n+1}^{n^{o}(j)} W(k)-W(k-1)-C(j) .
\end{aligned}
$$

By construction $W\left(n^{o}(j)\right)-W\left(n^{o}(j)-1\right)-C(j)>0$ and by assumption it holds for any 
$k<n^{o}(j)$ that

$$
W(k)-W(k-1)-C(j)>0
$$

A sum of positive elements has to be positive. A contradiction.

\section{A.6 Proof of Corollary 1}

Using the notation of Propositions 2 and 4 the variety of $R \& D$ projects in the market portfolio is $\left[0, \alpha_{1}\right]$ and the variety of $\mathrm{R} \& \mathrm{D}$ projects in the optimal portfolio is $\left[0, \alpha_{1}^{o}\right]$. Thus the market will underinvest in the variety of $\mathrm{R} \& \mathrm{D}$ projects if and only if $\alpha_{1}<\alpha_{1}^{o}$. As $C(\cdot)$ is increasing this is equivalent to $C\left(\alpha_{1}\right)<C\left(\alpha_{1}^{o}\right)$. By Propositions 2 and 4 it then holds $R(1)-r(0, N)<W(1)-W(0)$. Decomposing $W(1)$ into $C S(1)+R(1)$ and $W(0)$ into $C S(0)+N r(0, N)$ yields the desired result. Overinvestment and optimal investment cases are proven analogously.

\section{A.7 Proof of Proposition 6}

As assumptions 1, 2 and 4 hold, by Corollary 1 this market will underinvest in the variety of R\&D projects if and only if $C S(1)-W(0)+r(0, N)>0$. Denote with $q_{1}$ the quantity supplied by a monopolist with the innovation and with $q_{0}$ the quantity supplied by a single firm if no innovation is developed. As the innovation is drastic $P\left(q_{1}\right)<P\left(N q_{0}\right)$ or equivalently $q_{1}>N q_{0}$. We can write the consumer surplus as the difference between total utility and the total expense paid by consumers, so it holds $C S(1)=\int_{0}^{q_{1}} P(s) d s-P\left(q_{1}\right) q_{1}$. Welfare is total utility less the total cost of production, so it holds $W(0)=\int_{0}^{N q_{0}} P(s) d s-N \bar{c}\left(q_{0}\right)$. Then this market will underinvest if and only if:

$$
\int_{0}^{q_{1}} P(s) d s-P\left(q_{1}\right) q_{1}-\left[\int_{0}^{N q_{0}} P(s) d s-N \bar{c}\left(q_{0}\right)\right]+r(0, N)>0 .
$$

Subtracting the integrals and rearranging terms gives:

$$
\int_{N q_{0}}^{q_{1}} P(s) d s-P\left(q_{1}\right) q_{1}+N \bar{c}\left(q_{0}\right)+r(0, N)>0 .
$$


By assumption $P^{\prime}(\cdot)<0$ so that $\int_{N q_{0}}^{q_{1}} P(s) d s \geq\left(q_{1}-N q_{0}\right) P\left(q_{1}\right)$. The inequality above will hold whenever the following inequality holds:

$$
\left(q_{1}-N q_{0}\right) P\left(q_{1}\right)-P\left(q_{1}\right) q_{1}+N \bar{c}\left(q_{0}\right)+r(0, N)>0 .
$$

Rearranging gives:

$$
N \bar{c}\left(q_{0}\right)-N q_{0} P\left(q_{1}\right)+r(0, N)>0
$$

By assumption $\bar{c}^{\prime}(\cdot) \geq 0$ so that $\bar{c}\left(q_{0}\right)=\int_{0}^{q_{0}} \bar{c}^{\prime}(s) d s \geq\left(q_{0}-0\right) \bar{c}^{\prime}(0)$. The inequality above will hold whenever the following inequality holds:

$$
N q_{0}\left(\bar{c}^{\prime}(0)-P\left(q_{1}\right)\right)+r(0, N)>0 .
$$

As $r(0, N) \geq 0$ by rationality of firms and $\bar{c}^{\prime}(0)>P\left(q_{1}\right)$ by definition of a drastic process innovation, the above inequality always holds.

\section{A.8 Proof of Corollary 2}

Consider first the case where $\alpha_{k}^{o}<\alpha_{k}$. As $C(\cdot)$ is increasing then it holds $C\left(\alpha_{k}^{o}\right)<$ $C\left(\alpha_{k}\right)$. As assumptions 1, 2 and 4 hold, then Propositions 2 and 5 hold. Applying them yields $W(k)-W(k-1)<R(k)$ and decomposing the expression for $W(\cdot)$ yields $k R(k)+C S(k)-(k-1) R(k-1)-C S(k-1)<R(k)$. Rearranging gives:

$$
\delta(k)=[(k-1)(R(k)-R(k-1))]+[C S(k)-C S(k-1)]<0 .
$$

Hence $\alpha_{k}^{o}<\alpha_{k}$ if and only if $\delta(k)<0$. The other cases follow analogously.

\section{A.9 Proof of Proposition 2a}

Observe that the proof of Proposition 1 does not require Assumption 2. Proof of Proposition 2a exactly mirrors the proof of Proposition 2, except without setting $r(n, N)=0$ for all $n \geq 1$. In essence, Proposition 2 is a special case of Proposition 2a. 


\section{A.10 Example: Process innovation in a Cournot market}

As an illustrative example, consider a simple Cournot model with homogeneous products, linear costs and linear demand. Suppose that there are three firms facing inverse demand of the form

$$
P\left(q_{1}, q_{2}, q_{3}\right)=1-\left(q_{1}+q_{2}+q_{3}\right)
$$

where $q_{i}$ is the quantity supplied by the firm $i$. Denote with $\bar{c}$ the marginal cost of production with the old technology and with $\underline{c}$ the marginal cost of production with the new technology, where $\underline{c} \leq \bar{c} \leq 1$. That is, firms have the possibility to develop a process innovation which reduces their production cost from $\bar{c}$ to $\underline{c}$. The innovation is drastic if

$$
\bar{c} \geq \frac{1+\underline{c}}{2},
$$

where the right hand side of the inequality is the price which would be obtained if there was a monopolist with marginal cost $\underline{c}$ in the market. Suppose that the costs of research are given by

$$
C(j)=b \sqrt{\frac{j}{1-j}}, \quad j \in[0,1),
$$

where $b>0$ is a slope parameter. Observe that this choice of cost function implies $C(0)=0$ so that $m=N$, that is at least some of the innovation projects are developed by all the firms in the market.

Using standard methods, the profits in Cournot markets with $n$ firms and marginal costs $c$ are given by $\Pi(n, c)=(1-c)^{2} /(n+1)^{2}$. From this equation it is possible to derive the ex post payoffs:

$$
\begin{aligned}
r(0,3) & =\frac{(1-\bar{c})^{2}}{16}, & R(1) & =\frac{(1-\underline{c})^{2}}{4}, \\
R(2) & =\frac{(1-\underline{c})^{2}}{9}, & R(3) & =\frac{(1-\underline{c})^{2}}{16} .
\end{aligned}
$$

In order to be able to apply Proposition 2, we have to check if Assumptions 1 and 2 hold. Assumption 2 holds whenever Equation (2) is satisfied. In addition, Assumption 
1 holds whenever $\underline{c} \leq \bar{c} \leq 1$, which is assumed. ${ }^{16}$ Hence, Proposition 2 can be used to characterize the equilibrium R\&D portfolio.

Applying Proposition 2 yields the following $k$-firm frontiers for $k \in\{1,2,3\}$ :

$$
\begin{aligned}
\alpha_{3} & =\frac{R(3)^{2}}{b^{2}+R(3)^{2}}, \\
\alpha_{2} & =\frac{R(2)^{2}}{b^{2}+R(2)^{2}}, \\
\alpha_{1} & =\frac{(R(1)-r(0,3))^{2}}{b^{2}+(R(1)-r(0,3))^{2}} .
\end{aligned}
$$

All projects in the interval $\left[0, \alpha_{3}\right)$ are developed by all three firms whereas the projects in the interval $\left[\alpha_{3}, \alpha_{2}\right)$ are developed by two firms. Projects in the interval $\left[\alpha_{2}, \alpha_{1}\right)$ are developed by just one firm whereas the projects in the interval $\left[\alpha_{1}, 1\right)$ are not developed at all. Thus, if the successful project is from the interval $\left[0, \alpha_{1}\right)$, the market will successfully develop the innovation and all firms which invested in the successful project will compete with the production $\operatorname{costs} \underline{c}$. However, if the successful project is from the interval $\left[\alpha_{1}, 1\right)$ the market will not develop the innovation and all firms will compete with the production $\operatorname{costs} \bar{c}$.

Figure 1 (in Section 4) illustrates the equilibrium market portfolio in the case where $b=0.05, \bar{c}=3 / 4$ and $\underline{c}=1 / 2$.

\section{Merger of two firms}

Suppose now that two of the three firms merge, leaving everything else unchanged. That is, suppose that the merger affects only the number of firms which are active in the market. Denote with $\left\{r^{\prime}, R^{\prime}\right\}$ payoffs after the merger and with $\{r, R\}$ payoffs without the merger. Clearly, $\{r, R\}$ are the same as before. The new payoff functions are given

\footnotetext{
${ }^{16}$ If Assumption 2 is satisfied then the sufficient condition for Assumption 1 to hold is $\frac{(1-\underline{c})^{2}}{4}-$ $\frac{(1-\bar{c})^{2}}{16} \geq \frac{(1-\underline{c})^{2}}{9}$. If $\bar{c}=1$, the inequality is satisfied. If $\bar{c}<1$, the expression simplifies to $\left(\frac{1-\underline{c}}{1-\bar{c}}\right)^{2} \geq$ $\frac{9}{20}$, which is always satisfied because the left-hand expression is always greater than 1 .
} 
by:

$$
\begin{aligned}
r^{\prime}(0,2) & =\frac{(1-\bar{c})^{2}}{9}, \\
R^{\prime}(1) & =\frac{(1-\underline{c})^{2}}{4}, \\
R^{\prime}(2) & =\frac{(1-\underline{c})^{2}}{9} .
\end{aligned}
$$

It is immediately clear that $r^{\prime}(0,2)>r(0,3)$ whereas $R^{\prime}(1)=R(1)$ and $R^{\prime}(2)=R(2)$. The intuition behind this is that the merger increases profits in the market when all firms are active, because there are fewer competitors, hence $r^{\prime}(0,2)>r(0,3)$. However, due to the drastic nature of innovation, post-innovation profits only depend on the number of firms which successfully innovated, hence $R^{\prime}(1)=R(1)$ and $R^{\prime}(2)=R(2)$. As after the merger there are only two firms in the market, the maximum number of firms investing in any project is at most 2 .

Applying Proposition 2 yields $m^{\prime}=2<m=3, \alpha_{2}^{\prime}=\alpha_{2}$ but $\alpha_{1}^{\prime}<\alpha_{1}$. This is in line with results derived in Proposition 3. Figure 2 (in Section 5) graphically illustrates the change in the market portfolio of research projects after the merger.

\section{From Cournot to Bertrand competition}

Consider again the scenario with three firms and suppose that the type of competition changes from Cournot to Bertrand. This change can be interpreted as an increase in the intensity of competition among the firms. How will the market portfolio of research projects change? Applying Proposition 4, the variety of research projects developed will increase whereas the duplication of research projects will decrease.

From above we know that with three firms engaged in a Cournot competition, the market portfolio will be characterized by the maximum number of firms investing $m$ and the firm-frontiers $\alpha_{3}, \alpha_{2}$, and $\alpha_{1}$. The equilibrium values of the market under Bertrand competition are denoted with a prime. When there are multiple symmetric firms competing in a homogeneous goods Bertrand market, in equilibrium firms set prices equal to marginal cost of production and earn zero profits. Hence, the payoff functions will be $r^{\prime}(0,3)=0$ and $R^{\prime}(2)=R^{\prime}(3)=0$. The monopolist earns the same profits in both cases, 
that is $R^{\prime}(1)=R(1)=(1-\underline{c})^{2} / 4$.

As Assumptions 1 and 2 clearly hold, Proposition 2 can be applied. It immediately follows that $m^{\prime}=1$, hence $n(j)<n^{\prime}(j)$ for all $j<\alpha_{2}$. This drastic change in the amount of duplication is due to the fact that firms make no profits if there is a competitor, so firms choose to do no duplication at all. Simple calculations show that $\alpha_{1}^{\prime}>\alpha_{1}$. Figure 3 (in section 5) illustrates the change in the market portfolio of research projects due to the change of competition from Cournot to Bertrand.

\section{Market and optimal portfolios in a Cournot model}

Consider again the Cournot example from the appendix A.10. Social welfare generated in this product market by firms supplying total quantity $Q$ is given by:

$$
W_{Q}=\int_{0}^{Q} P(s) d s-Q c=\int_{0}^{Q}(1-s) d s-Q c=Q\left(1-\frac{Q}{2}-c\right)
$$

where $c$ is the constant marginal cost of production. Using standard results, the total quantity supplied in a Cournot market with $n$ firms is given by

$$
Q(n, c)=\frac{n(1-c)}{n+1}
$$

Assumptions 1 and 2 hold and simple calculations show that Assumption 4 holds as well. Hence Propositions 5 and 6 can be applied. Proposition 6 immediately informs us that there will be underinvestment in the variety of research projects. Figure 4 illustrates the difference between the optimal and the market portfolio in this market.

\section{References}

Acemoglu, D. And Zilibotti, F. "Was Prometheus Unbound by Chance? Risk, Diversification, and Growth." Journal of Political Economy, Vol. 105 (1997), pp. 709-751.

Aghion, P., Harris, C., Howitt, P., And Vickers, J. "Competition and Innova- 
tion: An Inverted-U Relationship." The Quarterly Journal of Economics, Vol. 120 (2005), pp. 701-728.

Aghion, P., Bloom, N., Blundell, R., And Griffith, R. "Competition, Imitation and Growth with Step-by-Step Innovation." The Review of Economic Studies, Vol. 68 (2001), pp. 467-492.

AkCigit, U. AND KERR, W.R. "Growth through Heterogeneous Innovations." PIER Working Paper no. 10-035, 2010.

Akcigit, U. And LiU, Q. "The Role of Information in Innovation and Competition." Journal of the European Economic Association (forthcoming).

Arrow, K. "Economic Welfare and the Allocation of Resources for Invention." In The Rate and Direction of Inventive Activity: Economic and Social Factors Princeton: Princeton University Press, 1962.

Bester, H. And Petrakis, E. "The Incentives for Cost Reduction in a Differentiated Industry." International Journal of Industrial Organization, Vol. 11 (1993), pp. $519-534$.

Bhattacharya, S. And Mookherjee, D. "Portfolio Choice in Research and Development." RAND Journal of Economics, Vol. 17 (1986), pp. 594-605.

CABral, L. "Bias in Market R\&D Portfolios." International Journal of Industrial Organization, Vol. 12 (1994), pp. 533-547.

Chatterjee, K. And Evans, R. "Rivals Search for Buried Treasure: Competition and Duplication in R\&D." RAND Journal of Economics, Vol. 35 (2004), pp. 160-183.

Dasgupta, P. And Maskin, E. "The Simple Economics of Research Portfolios." The Economic Journal, Vol. 97 (1987), pp. 581-595.

Farrell, J., Gilbert, R.J., And Katz, M.L. "Market Structure, Organizational Structure, and R\&D Diversity. In R. Arnott, B. Greenwald, R. Kanbur, and B. Nalebuff, eds., Economics for an Imperfect World: Essays in Honor of Joseph E. Stiglitz, Cambridge: MIT Press, 2003.

Fershtman, C. And Rubinstein, A. "A Simple Model of Equilibrium in Search Procedures." Journal of Economic Theory, Vol. 441 (1997), pp. 432-441.

Gilbert, R. "Looking for Mr. Schumpeter: Where are We in the Competition-Innovation 
Debate? In J. Adam, J. Lerner, and S. Stern, eds., Innovation Policy and the Economy 6, Cambridge: MIT Press, 2006.

Klette, T. And DE MezA, D. "Is the Market Biased against Risky R\&D?" RAND Journal of Economics, Vol. 17 (1986), pp. 133-139.

Kwon, I. "R\&D Portfolio and Market Structure." The Economic Journal, Vol. 120 (2010), pp. 313-323.

Mankiw N.G. And Whinston, M.D. "Free Entry and Social Inefficiency." RAND Journal of Economics, Vol. 17 (1986), pp. 48-58.

Quirmbach, H.C. "R\&D: Competition, Risk, and Performance." RAND Journal of Economics, Vol. 24 (1993), pp. 157-197.

Reynolds, S.S. And IsAac, R.M. "Stochastic Innovation and Product Market Organization." Economic Theory, Vol. 2 (1992), pp. 525-545.

Robinson, C.K. "Leap-frog and Other Forms of Innovation: Protecting the Future for High-Tech and Emerging Industries Through Merger Enforcement." Address before the American Bar Association, Chicago, IL, June 10, 1999.

Rubinfeld, D.L. And Hoven, J. "Innovation and Antitrust Enforcement" In J. Ellig, ed., Dynamic Competition and Public Policy: Technology, Innovation and Antitrust Issues, New York: Cambridge University Press, 2001.

SAH, R.K. AND Stiglitz, J.E. "The Invariance of Market Innovation to the Number of Firms." RAND Journal of Economics, Vol. 18 (1987), pp. 98-108.

Schmidt., K.M. "Managerial Incentives and Product Market Competition." The Review of Economic Studies, Vol. 64 (1997), pp. 191-213.

Schmutzler, A. "Competition and Investment - A Unified Approach?" International Journal of Industrial Organization (2013), pp. 477-487.

Segal, I. And Whinston, M.D. "Antitrust in Innovative Industries." The American Economic Review, Vol. 97 (2007), pp. 1703-1730.

SenA, V. "The Return of the Prince of Denmark: A Survey on Recent Developments in the Economics of Innovation." The Economic Journal, Vol. 114 (2004), pp. F312-F332.

U.S. Department of Justice and the Federal Trade Commission. Horizontal 
Merger Guidelines, (2010). http://www.justice.gov/atr/public/guidelines/ hmg-2010.html. Accessed on May 19, 2015.

van Cayseele, P.J.G. "Market Structure and Innovation: a Survey of the Last Twenty Years." De Economist (1998), pp. 391-417.

Vives, X. "Innovation and Competitive Pressure." The Journal of Industrial Economics, Vol. 56 (2008), pp. 419-469. 


\title{
B Online Appendix - Not for Publication
}

\author{
The Road Not Taken: \\ Competition and the R\&D Portfolio \\ Igor Letina, University of Zurich
}

In this Appendix I consider four extensions of the basic model. First two deal with the possibility that a merger could generate efficiencies which could overturn the result that a merger decreases the variety of approaches to innovation. In Section B.2 I consider a mixed strategy equilibirum and show that the equilibrium structure and determinants of comparative static results found for pure strategy equilibria are robust. Finally, in Section B.3 I consider the case when the research budgets are limited or when financing of research is costly. Proofs are presented sequentially in the end of the Appendix.

\section{B.1 Efficiency defense}

\section{General cost reduction}

Consider the original setting, but suppose that if two firms merge, they become more efficient at developing innovations. That is, suppose that for the merged firm the fixed cost of developing any given approach $j$ is given by $\tilde{C}(j ; \epsilon):[0,1) \rightarrow \mathbb{R}^{+}$such that $\tilde{C}(j ; \epsilon) \leq C(j)$ for all $j$. Like $C$, assume that $\tilde{C}$ is continuous, differentiable, strictly increasing and that $\lim _{j \rightarrow 1} \tilde{C}(j ; \epsilon)=\infty$. Finally, suppose that in this setting $\epsilon$ captures the size of the efficiency gains resulting from the merger, such that $\partial \tilde{C}(j ; \epsilon) / \partial \epsilon<0$. Simple functional forms that satisfy these assumptions (for the appropriate domain of $\epsilon$ ) are: (i) additive $\tilde{C}(j ; \epsilon)=C(j)-\epsilon$ and (ii) multiplicative $\tilde{C}(j ; \epsilon)=(1-\epsilon) C(j)$. Let the number of symmetric firms with innovation cost functions $C(j)$ in the pre-merger market be $N$. Suppose that after the merger, the merged firm has the cost function $\tilde{C}(j ; \epsilon)$ and that the remaining $N-2$ firms are active with cost functions $C(j)$.

In this setting, if the efficiency gain from the merger is sufficiently large, there will be no loss of diversity in the approaches to innovation as a consequence of the merger. 
Proposition 7 (Merger with general cost reductions).

Suppose that Assumptions 1, 2, and 3 hold and that the merger results in efficiency gains as above. Then:

1. A PSE in the post-merger market always exists.

2. In any PSE in the post-merger market the set of developed approaches is $\left[0, \tilde{\alpha}_{1}\right)$, where $\tilde{\alpha}_{1}$ is given by $\tilde{C}\left(\tilde{\alpha}_{1} ; \epsilon\right)=R(1)-r(0, N-1)$.

3. If the technology frontier in the market without a merger is given by $\alpha_{1}$, then the merger does not reduce the variety of approaches to innovation if and only if

$$
C\left(\alpha_{1}\right)-\tilde{C}\left(\alpha_{1} ; \epsilon\right) \geq r(0, N-1)-r(0, N)
$$

From Proposition 3 we know that a merger, via the Arrow effect, reduces the incentives to invest. This is captured by the right-hand side of the inequality (4). However, Proposition 7 states that if the efficiency caused by the merger is large enough, which is given by the left-hand side of the inequality (4), it can outweigh the decrease in the incentive to invest. In this case, the merger does not lead to a decrease in the variety of approaches to innovation. In the case of additive efficiency gains, that is if $\tilde{C}(j ; \epsilon)=C(j)-\epsilon$, the inequality (4) would simplify to $\epsilon \geq r(0, N-1)-r(0, N)$. In the case of multi-

plicative efficiency gains, that is if $\tilde{C}(j ; \epsilon)=(1-\epsilon) C(j)$, the inequality (4) simplifies to $\epsilon C\left(\alpha_{1}\right) \geq r(0, N-1)-r(0, N)$. It is clear that there always exists $\epsilon$ large enough such that these inequalities are satisfied, and that such a merger would not lead to a decrease in the variety of approaches to innovation.

\section{Approach-specific synergies}

In the previous section, I considered a situation in which a merger between any two firms leads to the same efficiency gains. Now, suppose that each firm has some specific knowledge and that if the two firms merged, they could combine this specific knowledge in a way that would enable the merged entity to conduct research over some specific interval of approaches more efficiently. In this setting, it will not only be the size of 
the efficiency gains that will be required for a successful efficiency defense, but also that the efficiency gains occurs over approaches that would not have been developed in the post-merger market absent the efficiency gains.

For concreteness, consider this simple extension of the model. Suppose that each firm $i \in\{1, \ldots, N\}$ is located on the unit line in an equidistant manner. That is, the location of the firm is given by $i /(N+1)$. Firm's location represents its specific knowledge. On it its own, this knowledge is worthless. However, suppose that firm $i$ merged with some firm $l \in\{1, \ldots, N\}, i \neq l$. Then the merged entity would receive efficiency gains over an interval midway between the location of the firms $i$ and $l$. That is, the merged entity is more efficient over an interval

$$
\left[\frac{i+l}{2(N+1)}-\delta, \frac{i+l}{2(N+1)}+\delta\right)
$$

for some $0<\delta \leq 1 /(N+1) .{ }^{17}$ For simplicity, suppose that on the above interval the cost of developing an approach is zero for the merged entity. That is, a firm which has not merged has the innovation cost function $C(j)$ and the merged firm (where the merging firms are $i$ and $l$ ) has the innovation cost function

$$
\tilde{C}_{i, l}(j)=\left\{\begin{array}{ll}
0 & \text { if } j \in\left[\frac{i+l}{2(N+1)}-\delta, \frac{i+l}{2(N+1)}+\delta\right) \\
C(j) & \text { otherwise }
\end{array} .\right.
$$

In this setting, a merger will not lead to a decrease in the variety of approaches if the efficiency gain covers large enough interval ( $\delta$ is large enough) and if the efficiency gain occurs over projects which would not be developed absent the efficiency gain. The latter depends on which firms actually merge. Thus, for the same size of the efficiency gain from the merger, some mergers will lead to a decrease in the variety of approaches whereas others will not.

Proposition 8 (Merger with approach-specific synergies).

Suppose that Assumptions 1, 2, and 3 hold and that the merger results in efficiency gains

\footnotetext{
${ }^{17}$ The upper bound is a simplification that ensures that efficiency gains are always in the unit interval. It would be straightforward to remove it, at the cost of more cumbersome notation.
} 
as above. Then, if firms $i$ and $l$ merge:

1. A PSE in the post-merger market always exists.

2. In any PSE in the post-merger market the set of developed approaches is $\left[0, \tilde{\alpha}_{1}\right) \cup$ $\left[\frac{i+l}{2(N+1)}-\delta, \frac{i+l}{2(N+1)}+\delta\right)$, where $\tilde{\alpha}_{1}$ is given by $C\left(\tilde{\alpha}_{1}\right)=R(1)-r(0, N-1)$.

3. If the technology frontier in the market without a merger is given by $\alpha_{1}$, then the merger does not reduce the variety of approaches to innovation if and only if

$$
\int_{x \in\left[0, \tilde{\alpha}_{1}\right) \cup\left[\frac{i+l}{2(N+1)}-\delta, \frac{i+l}{2(N+1)}+\delta\right)} d x \geq \alpha_{1} .
$$

As the innovation cost function for the merged firm is not strictly increasing, the set of developed approaches need not be convex any more. However, the intuition is clear - the efficiency gain must be both large enough and must materialize over the projects which would not have been developed otherwise for the efficiency defense to be successful.

\section{B.2 Mixed strategies}

Consider the original setting, but suppose that firms are using mixed strategies. As a simplifying assumption, I will consider only the following pure strategy space

$$
\mathcal{I}^{m}=\{0\} \cup\{[0, j): j \in(0,1)\}
$$

and I will look only at symmetric mixed strategy equilibria (SMSE). Because now the pure strategy of a firm is restricted to choosing an interval $[0, j)$, it can be identified with the upper bound of the interval $j$. Denote with $f_{i}(j)$ the density that the firm $i$ chooses the interval $[0, j)$ and with $F_{i}(j)$ the related cumulative distribution function.

Proposition 9 (Characterization of SMSE). Suppose $N=2$ and the Assumptions 1 and 
2 hold. Then the unique SMSE is characterized by the cumulative distribution function:

$$
F(j)=\left\{\begin{array}{lll}
0 & \text { if } & \frac{C(j)-R(2)}{R(1)-r(0,2)-R(2)}<0 \\
\frac{C(j)-R(2)}{R(1)-r(0,2)-R(2)} & \text { if } & \frac{C(j)-R(2)}{R(1)-r(0,2)-R(2)} \in[0,1] \\
1 & \text { if } & \frac{C(j)-R(2)}{R(1)-r(0,2)-R(2)}>1
\end{array}\right.
$$

for $j \in[0,1)$.

Suppose that $R(2)-C(0)>0$. In pure actions, by Proposition 2 it holds: $m=2$, $C\left(\alpha_{1}\right)=R(1)-r(0, N)$ and $C\left(\alpha_{2}\right)=R(2)$. Thus, both firms will invest in the interval $\left[0, \alpha_{1}\right)$, only one firm will invest in the interval $\left[\alpha_{1}, \alpha_{2}\right)$ and no firm will invest in $\left[\alpha_{2}, 0\right)$. Now consider SMSE. By Proposition 9, for $j \in\left[0, \alpha_{1}\right)$ it holds $F(j)=0$, thus both firms invest in this interval with probability 1. For $j \in\left(\alpha_{1}, \alpha_{2}\right)$ it holds $0<F(j)<1$, thus firms invest with some probability less then one. If $j \in\left[\alpha_{2}, 0\right)$, then $F(j)=1$, so that firms do not invest in this interval. Similar results hold if $R(2)-C(0) \leq 0$. Thus, the basic structure of the model is the same in both pure and mixed strategy equilibria. In particular the $k$-firm frontiers are the same. Furthermore, comparative statics results regarding variety of projects undertaken remain qualitatively the same, as anything that affects the one-firm frontier has qualitatively the same effect both in pure action and in mixed strategy equilibria. Figure 8 illustrates the difference between the (expected) equilibrium market portfolios for the Cournot duopoly example from the appendix A.10. The mixed strategy equilibrium is "smoother" than the pure strategy equilibrium. The reason for this is that the integer problem is not present in the mixed strategy setting. In pure strategy equilibrium, some projects have higher expected profits than others (i.e. project $\alpha_{2}+\epsilon$ is more profitable than $\alpha_{2}-\epsilon$ for some small positive $\epsilon$ ). In mixed strategy equilibria, all projects in the interval where the mixing occurs have the same expected profits. 


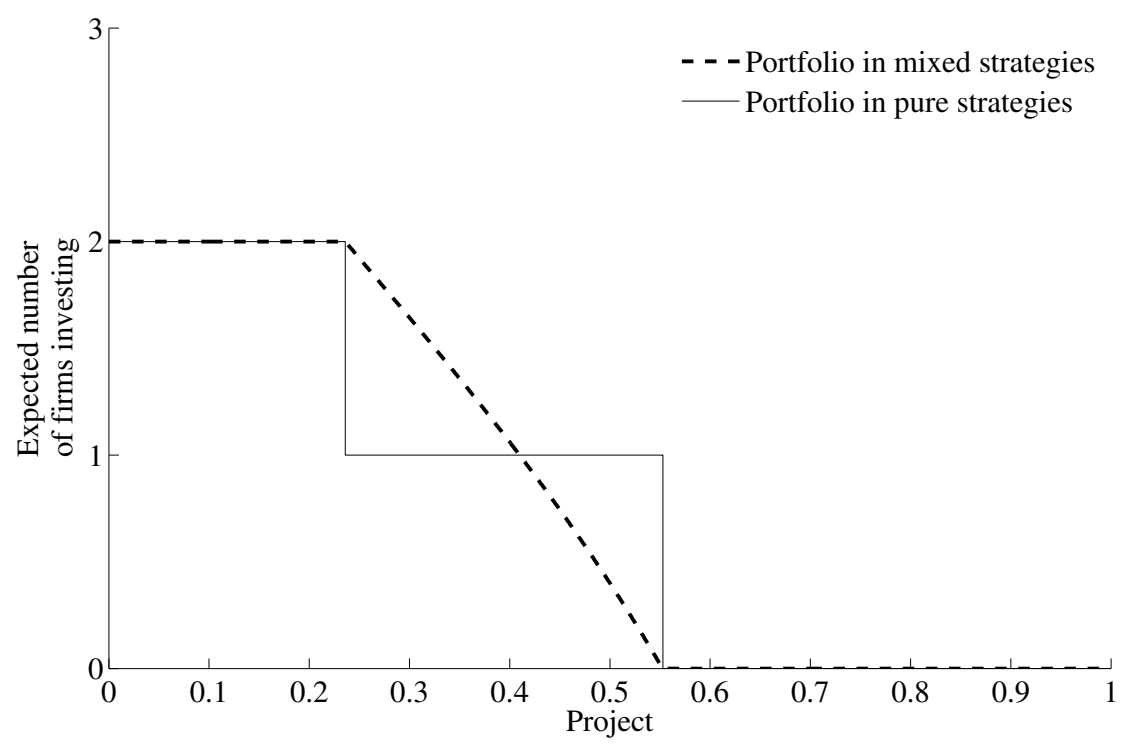

Figure 8: Symmetric mixed strategy equilibrium.

\section{B.3 Limited budget and costly financing}

This section considers the case where firms face an exogenous constraint on their research budgets. This constraint can take the form of a budget constraint, or it can (equivalently) take the form of costly financing for research. The main result is that a binding budget constraint or a costly source of financing imposes a positive opportunity cost on investments in research projects, but that the main mechanics of the model remain unchanged.

First, suppose that there are two firms in a market and that each firm has a budget $B$ and suppose that the budget is binding, in the sense that firms would want to invest more in research if they had more resources. ${ }^{18}$ Then the following result is obtained:

Proposition 10 (Equilibrium in a game with limited budget).

Suppose that Assumptions 1 and 2 hold, and that there are two firms with a budget B. Then, a PSE always exists, the induced PSE market portfolio is unique and any investment plan which induces a portfolio identical to the market PSE portfolio is itself a PSE. Furthermore, there exists a unique $\beta>0$ such that:

1. the maximum number of firms investing in any project $m^{b}$ is given by

$$
m^{b}=\max _{\{1,2\}} n \quad \text { s.t. } \quad R(n)-r(n-1, N)-C(0)>\beta .
$$

\footnotetext{
${ }^{18}$ Formally, if $m=2$ then $2 B<2 \int_{0}^{\alpha_{2}} C(j) d j+\int_{\alpha_{2}}^{\alpha_{1}} C(j) d j$ and if $m=1$ then $2 B<\int_{0}^{\alpha_{1}} C(j) d j$.
} 
2. Firm frontiers are determined by

$$
\begin{gathered}
R(1)-r(0, N)-C\left(\alpha_{1}^{b}\right)= \\
R\left(m^{b}\right)-r\left(m^{b}-1, N\right)-C\left(\alpha_{m}^{b}\right)=\beta .
\end{gathered}
$$

3. Let $\alpha_{m+1}^{b}=0$ and $\alpha_{0}^{b}=1$. The total expenditure is

$$
m \int_{0}^{\alpha_{m}^{b}} C(j) d j+(m-1) \int_{\alpha_{m}^{b}}^{\alpha_{m-1}^{b}} C(j) d j=2 B
$$

Then the PSE portfolio $n^{b}(j)$ is given by

$$
n^{b}(j)=k \quad \text { if } \quad j \in\left[\alpha_{k+1}^{b}, \alpha_{k}^{b}\right) .
$$

As can be seen from conditions 1. and 2., the basic form of the market equilibrium portfolio will remain unchanged. The only difference is that the budget constraint will impose positive opportunity $\operatorname{cost} \beta$ on the choice of research projects, as opposed to the unconstrained equilibrium where the opportunity costs was 0 . In the scenario where firms can borrow unlimited funds at some positive price, the equilibrium characterized above still holds, but now $\beta$ is exogenously given and as a function of the cost of financing.

\section{B.4 Proof of Proposition 7}

I prove each of the three statements contained in Proposition 7 in turn. The proof is analogous to the proof of Proposition 1.

Lemma 7 (Existence). A PSE in the post-merger market always exists.

I provide a constructive proof of Lemma 7 in three steps. Step 1 constructs the candidate equilibrium investment plan $\tilde{I}$. Step 2 proves that no firm can increase its expected profits by making additional investments. Step 3 proves that no firm can increase its expected profits by reducing investments. Finally, notice that any deviation from the investment plan $\tilde{I}$ can be written as a collection of investments and divestments and by Steps 2 and 3, each such investment and divestment decreases expected profits and hence 
any such collection must decrease expected profits. Thus, no firm can profitably deviate from the investment plan $\tilde{I}$ and then, by definition, $\tilde{I}$ is an equilibrium.

Step 1. Constructing the candidate equilibrium.

Given a game, define $m$ such that

$$
m=\max _{\{1, \ldots, N-1\}} n
$$

s.t. $R(n)-r(n-1, N-1)-C(0)>0$

As by assumption $R(1)-r(0, N-1)-C(0)>0$, a solution to this maximization problem always exists.

Next, calculate each $\tilde{\alpha}_{1}, \alpha_{2}, \ldots, \alpha_{m}$ such that the following condition holds:

$$
\begin{gathered}
R(1)-r(0, N-1)-\tilde{C}\left(\tilde{\alpha}_{1} ; \epsilon\right)= \\
R(2)-C\left(\alpha_{2}\right)= \\
R(3)-C\left(\alpha_{3}\right)= \\
\vdots \\
R(m)-C\left(\alpha_{m}\right)=0 .
\end{gathered}
$$

By construction it holds $R(m)-r(m-1, N)-C(0)>0$ and by Assumption 1 the reward of innovation are non-increasing, so the inequality holds for all $k<m$. As $\tilde{C}(j ; \epsilon) \leq$ $C(j)$, the inequality also holds for the merged firm. As costs of innovation approach infinity as $j \rightarrow 1$, values $\tilde{\alpha}_{1}, \alpha_{2}, \ldots, \alpha_{m}$ always exist by the Intermediate Value Theorem. Furthermore, as $C(j)$ is increasing, $\tilde{C}(j ; \epsilon) \leq C(j)$, and by applying Assumption 1 it is easy to see that $\tilde{\alpha}_{1} \geq \alpha_{2} \geq \cdots \geq \alpha_{m}$.

Observe that $N-1 \geq m$. Label the merged firm with subscript $i=1$ and all other firms with $i \in\{2, \ldots, N-1\}$. For the merged firm, let $\tilde{I}_{1}=\left[0, \tilde{\alpha}_{1}\right)$. For each $i \in\{2, \ldots, m\}$, let $\tilde{I}_{i}=\left[0, \alpha_{i}\right)$. For each $i \in\{m+1, \ldots, N-1\}$ let $\tilde{I}_{i}=\emptyset$. I will demonstrate that $\tilde{I}$ is an equilibrium.

Step 2. Suppose that $\tilde{I}$ is constructed as above. Then no firm can increase its expected 
profits by making additional investments.

Proof. First observe that for all firms $i \in\{2, \ldots, N-1\}$ the argument is identical as in the proof of Proposition 1, as the investment decision of the firm only depends on their investment costs and the number of firms investing in any given project. Thus we only need to show that the merged firm cannot increase profits by making additional investments. This holds by construction. The merged firm already invests in the entire interval $\left[0, \tilde{\alpha}_{1}\right)$. For any $j>\tilde{\alpha}_{1}$ it holds $R(1)-r(0, N-1)-\tilde{C}(j ; \epsilon)<0$ as $\tilde{C}(j ; \epsilon)$ is strictly increasing in $j$. Thus, no additional profitable investments exist for the merged firm.

Step 3. Suppose that $\tilde{I}$ is constructed as above. Then no firm can increase its expected profits by decreasing investments.

Proof. Similar to the argument in the previous step, it is sufficient to show that the merged firm cannot increase profits by decreasing investments. First, observe that for $j \in\left[\alpha_{2}, \tilde{\alpha}_{1}\right)$ the investment is profitable as it holds $R(1)-r(0, N-1)-\tilde{C}(j ; \epsilon)>0$ for all $j$ in the interval. For all $j$ in $\left[0, \alpha_{2}\right)$ it holds $R(n(j, \tilde{I}))-C(j)>0$ (otherwise non-merged firms would have an incentive to divest) and as $\tilde{C}(j ; \epsilon) \leq C(j)$, it also holds $R(n(j, \tilde{I}))-\tilde{C}(j ; \epsilon)>0$ for all $j \in\left[0, \alpha_{2}\right)$. Hence, the merged firm cannot increase profits by divesting.

Lemma 8. In any PSE in the post-merger market the set of developed approaches is $\left[0, \tilde{\alpha}_{1}\right)$, where $\tilde{\alpha}_{1}$ is given by $\tilde{C}\left(\tilde{\alpha}_{1} ; \epsilon\right)=R(1)-r(0, N-1)$.

Proof. Suppose not. Then, either there exist an interval $l \subseteq\left[0, \tilde{\alpha}_{1}\right)$ where no firm invests, or there exists an interval $l^{\prime} \subseteq\left[\tilde{\alpha}_{1}, 1\right)$ where at least one firm invests, or both. First suppose that an interval $l$ exists. As $\tilde{C}(j ; \epsilon)$ is strictly increasing, then for all $j \in l$ it holds $\tilde{C}(j ; \epsilon)<R(1)-r(0, N-1)$. Hence the merged firm can profitably invest in the subset of $l$. Next, suppose an interval $l^{\prime}$ exists. Observe that for any $j>\tilde{\alpha}_{1}$ it holds $C(j) \geq \tilde{C}(j ; \epsilon)>R(1)-r(0, N-1)$. By Assumption 1 it then also holds $C(j) \geq \tilde{C}(j ; \epsilon)>R(k)$ for all $k \geq 2$. Thus, no firm can profitably invest any subset of $l^{\prime}$. 
Lemma 9. If the technology frontier in the market without a merger is given by $\alpha_{1}$, then the merger does not reduce the variety of approaches to innovation if and only if

$$
C\left(\alpha_{1}\right)-\tilde{C}\left(\alpha_{1} ; \epsilon\right) \geq r(0, N-1)-r(0, N) \text {. }
$$

Proof. The merger does not reduce variety if and only if $\tilde{\alpha}_{1} \geq \alpha_{1}$. As $\tilde{C}(j ; \epsilon)$ is strictly increasing, this will hold if and only if $\tilde{C}\left(\alpha_{1} ; \epsilon\right) \leq R(1)-r(0, N-1)$. By Proposition 2 , we know that $C\left(\alpha_{1}\right)=R(1)-r(0, N)$. Subtracting the above inequality, the claim follows.

\section{B.5 Proof of Proposition 8}

I prove each of the three statements contained in Proposition 8 in turn. The proof is analogous to the proof of Proposition 1.

Lemma 10 (Existence). A PSE in the post-merger market always exists.

I provide a constructive proof of Lemma 10 in three steps, analogous to the proof of Lemma 7.

Step 1. Constructing the candidate equilibrium.

Given a game, define $m$ such that

$$
\begin{gathered}
m=\max _{\{1, \ldots, N-1\}} n \\
\text { s.t. } R(n)-r(n-1, N-1)-C(0)>0
\end{gathered}
$$

As by assumption $R(1)-r(0, N-1)-C(0)>0$, a solution to this maximization problem always exists. 
Next, calculate each $\tilde{\alpha}_{1}, \alpha_{2}, \ldots, \alpha_{m}$ such that the following condition holds:

$$
\begin{gathered}
R(1)-r(0, N-1)-C\left(\tilde{\alpha}_{1}\right)= \\
R(2)-C\left(\alpha_{2}\right)= \\
R(3)-C\left(\alpha_{3}\right)= \\
\vdots \\
R(m)-C\left(\alpha_{m}\right)=0 .
\end{gathered}
$$

By construction it holds $R(m)-r(m-1, N)-C(0)>0$ and by Assumption 1 the reward of innovation are non-increasing, so the inequality holds for all $k<m$. As costs of innovation approach infinity as $j \rightarrow 1$, values $\tilde{\alpha}_{1}, \alpha_{2}, \ldots, \alpha_{m}$ always exist by the Intermediate Value Theorem. Furthermore, by Assumption 1, it is easy to see that $\tilde{\alpha}_{1} \geq \alpha_{2} \geq \cdots \geq \alpha_{m}$.

Observe that $N-1 \geq m$. Label the merged firm with subscript $i=1$ and all other firms with $i \in\{2, \ldots, N-1\}$. For the merged firm, let $\tilde{I}_{1}=\left[0, \tilde{\alpha}_{1}\right) \cup\left[\frac{i+l}{2(N+1)}-\delta, \frac{i+l}{2(N+1)}+\delta\right)$. For each $i \in\{2, \ldots, m\}$, let $\tilde{I}_{i}=\left[0, \alpha_{i}\right)$. For each $i \in\{m+1, \ldots, N-1\}$ let $\tilde{I}_{i}=\emptyset$. I will demonstrate that $\tilde{I}$ is an equilibrium.

Step 2. Suppose that $\tilde{I}$ is constructed as above. Then no firm can increase its expected profits by making additional investments.

Proof. For firms $i \in\{2, \ldots, N-1\}$ the argument is identical as in the proof of Proposition 7. Thus we only need to show that the merged firm cannot increase profits by making additional investments. The merged firm already invests in the entire set $\left[0, \tilde{\alpha}_{1}\right) \cup\left[\frac{i+l}{2(N+1)}-\delta, \frac{i+l}{2(N+1)}+\delta\right)$. For any $j>\tilde{\alpha}_{1}$ and $j \notin\left[\frac{i+l}{2(N+1)}-\delta, \frac{i+l}{2(N+1)}+\delta\right)$ it holds $R(1)-r(0, N-1)-\tilde{C}(j)<0$ as $C(j)$ is strictly increasing. Thus, no additional profitable investments exist for the merged firm.

Step 3. Suppose that $\tilde{I}$ is constructed as above. Then no firm can increase its expected profits by decreasing investments.

Proof. Similar to the argument in the previous step, it is sufficient to show that the merged firm cannot increase profits by decreasing investments. First, observe that for $j \in\left[\alpha_{2}, \tilde{\alpha}_{1}\right)$ the investment is profitable as it holds $R(1)-r(0, N-1)-C(j)>0$ for all $j$ in 
the interval. For all $j$ in $\left[0, \alpha_{2}\right)$ it holds $R(n(j, \tilde{I}))-C(j)>0$ (otherwise non-merged firms would have an incentive to divest) and as $\tilde{C}(j) \leq C(j)$, it also holds $R(n(j, \tilde{I}))-\tilde{C}(j)>0$ for all $j \in\left[0, \alpha_{2}\right)$. For all $j \in\left[\frac{i+l}{2(N+1)}-\delta, \frac{i+l}{2(N+1)}+\delta\right)$ the investment is costless. Hence, the merged firm cannot increase profits by divesting.

Lemma 11. In any PSE in the post-merger market the set of developed approaches is $\left[0, \tilde{\alpha}_{1}\right) \cup\left[\frac{i+l}{2(N+1)}-\delta, \frac{i+l}{2(N+1)}+\delta\right)$, where $\tilde{\alpha}_{1}$ is given by $C\left(\tilde{\alpha}_{1}\right)=R(1)-r(0, N-1)$.

Proof. Suppose not. Then, either there exists an interval $l \subseteq\left[0, \tilde{\alpha}_{1}\right)$ or an interval $l^{\prime} \subseteq\left[\frac{i+l}{2(N+1)}-\delta, \frac{i+l}{2(N+1)}+\delta\right)$ where no firm invests, or there exists an interval $l^{\prime \prime} \subseteq[0,1) \backslash$ $\left(\left[0, \tilde{\alpha}_{1}\right) \cup\left[\frac{i+l}{2(N+1)}-\delta, \frac{i+l}{2(N+1)}+\delta\right)\right)$ where at least one firm invests. First suppose that an interval $l$ exists. Because by construction it holds $C(j ;)<R(1)-r(0, N-1)$ for all $j<\tilde{\alpha}_{1}$, any firm can profitably invest in the set $l$. Next, suppose $l^{\prime}$ exists. The merged firm can invest in the set $l^{\prime}$ without any cost, hence it can increase its expected profit by investing. Finally, suppose an interval $l^{\prime \prime}$ exists. Observe that for any $j>\tilde{\alpha}_{1}$ and $j \notin\left[\frac{i+l}{2(N+1)}-\delta, \frac{i+l}{2(N+1)}+\delta\right)$ it holds $\tilde{C}(j)>R(1)-r(0, N-1)$. By Assumption 1 it then also holds $C(j) \geq \tilde{C}(j)>R(k)$ for all $k \geq 2$. Thus, no firm can profitably invest any subset of $l^{\prime \prime}$.

Lemma 12. If the technology frontier in the market without a merger is given by $\alpha_{1}$, then the merger does not reduce the variety of approaches to innovation if and only if

$$
\int_{x \in\left[0, \tilde{\alpha}_{1}\right) \cup\left[\frac{i+l}{2(N+1)}-\delta, \frac{i+l}{2(N+1)}+\delta\right)} d x \geq \alpha_{1}
$$

Proof. Without the merger, the set of developed approaches by Proposition 2 is $\left[0, \alpha_{1}\right)$. The result follows by Claim 2 of the Proposition.

\section{B.6 Proof of Proposition 9}

Suppose, without loss of generality, that the firm 2 invests according to some probability density function $f_{2}$, with the cumulative density function $F_{2}$. Consider any pure action 
$x_{1}$ of firm 1 . The profit of the firm 1 can be expressed as:

$$
\begin{aligned}
\pi_{1}\left(x_{1} \mid F_{2}\right)= & -\int_{0}^{x_{1}} C(j) d j+\int_{0}^{x_{1}}\left[\int_{0}^{x_{2}} R(2) d j+\int_{x_{2}}^{x_{1}} R(1) d j+\int_{x_{1}}^{1} r(0,2) d j\right] f_{2}\left(x_{2}\right) d x_{2}+ \\
& +\int_{x_{1}}^{1}\left[\int_{0}^{x_{1}} R(2) d j+\int_{x_{2}}^{1} r(0,2) d j\right] f_{2}\left(x_{2}\right) d x_{2} .
\end{aligned}
$$

Deriving:

$$
\begin{aligned}
\frac{d \pi_{1}\left(x_{1} \mid F_{2}\right)}{d x_{1}}= & -C\left(x_{1}\right)+\left[\int_{0}^{x_{1}} R(2) d j+\int_{x_{1}}^{x_{1}} R(1) d j+\int_{x_{1}}^{1} r(0,2) d j\right] f_{2}\left(x_{1}\right)- \\
& -\left[\int_{0}^{x_{1}} R(2) d j+\int_{x_{1}}^{1} r(0,2) d j\right] f_{2}\left(x_{1}\right)+ \\
& +\int_{0}^{x_{1}}[R(1)-r(0,2)] f_{2}\left(x_{2}\right) d x_{2}+\int_{x_{1}}^{1} R(2) f_{2}\left(x_{2}\right) d x_{2}
\end{aligned}
$$

and simplifying:

$$
\frac{d \pi_{1}\left(x_{1} \mid F_{2}\right)}{d x_{1}}=-C\left(x_{1}\right)+[R(1)-r(0,2)] F_{2}\left(x_{1}\right)+R(2)\left(1-F_{2}\left(x_{1}\right)\right)
$$

Next, use the assumption that the equilibrium is symmetric, that is $F_{1}=F_{2}=F$. In equilibrium it has to hold $d \pi_{1}\left(x_{1} \mid F\right) / d x_{1}=0$ for all $x_{1}$ in the support of $f$. This condition is uniquely satisfied by

$$
\tilde{F}(j)=\frac{C(j)-R(2)}{R(1)-r(0,2)-R(2)}
$$

for $j$ in the support of $f$.

Observe that $\tilde{F}$ is strictly increasing and, for all $j$ such that $\tilde{F}(j)<0$ it follows that $d \pi_{1}\left(x_{1}, F\right) / d x_{1}>0$, and for all $j$ such that $\tilde{F}(j)>1$ it follows that $d \pi_{1}\left(x_{1}, F_{2}\right) / d x_{1}<0$. Hence, the unique symmetric equilibrium is given by the profile $(F, F)$ where

$$
F(j)=\left\{\begin{array}{lll}
0 & \text { if } & \frac{C(j)-R(2)}{R(1)-r(0,2)-R(2)}<0 \\
\frac{C(j)-R(2)}{R(1)-r(0,2)-R(2)} & \text { if } & \frac{C(j)-R(2)}{R(1)-r(0,2)-R(2)} \in[0,1] \\
1 & \text { if } & \frac{C(j)-R(2)}{R(1)-r(0,2)-R(2)}>1
\end{array}\right.
$$


for $j \in[0,1)$.

\section{B.7 Proof of Proposition 10}

I prove this statement in three steps. First I show that some $\beta$ satisfying all conditions in the proposition always exists and is unique. Next, I construct an investment plan inducing the same portfolio as the one in Proposition 10. Finally I show that the constructed investment plan is an equilibrium and that any investment plan inducing the same portfolio is an equilibrium as well.

Lemma 13. $\beta$ always exists and is unique.

Proof. Define functions $\psi^{1}(\beta):\left[0, \beta^{1}\right] \rightarrow \mathbb{R}^{+}, \psi^{2}(\beta):\left[0, \beta^{2}\right] \rightarrow \mathbb{R}^{+}$such that

$$
\begin{aligned}
& \psi^{1}(\beta)=\int_{0}^{C^{-1}(R(1)-r(0,2)-\beta)} C(j) d j \\
& \psi^{2}(\beta)=\int_{0}^{C^{-1}(R(2)-\beta)} C(j) d j+\int_{0}^{C^{-1}(R(1)-r(0,2)-\beta)} C(j) d j
\end{aligned}
$$

with $\beta^{1}=R(1)-r(0,2)-C(0)$ and $\beta^{2}=R(2)-C(0)$. As $C(\cdot)$ is continuous, strictly increasing and defined on an interval, its inverse is continuous and strictly increasing as well. Hence both $\psi^{1}(\beta)$ and $\psi^{1}(\beta)$ are continuous and strictly decreasing. Furthermore, by Assumption 1 it holds $\beta^{1} \geq \beta^{2}$.

Either $(i) \psi^{1}\left(\beta^{2}\right) \geq 2 B$ or $(i i) \psi^{1}\left(\beta^{2}\right)<2 B$. If $(i)$ is true, $\psi^{1}\left(\beta^{2}\right) \geq 2 B$ and $\psi^{1}\left(\beta^{1}\right)=$ $0<2 B$. By the Intermediate Value Theorem there exists some $\beta^{*} \in\left[\beta^{2}, \beta^{1}\right)$ such that $\psi^{1}\left(\beta^{*}\right)=2 B$ and furthermore $\beta^{*}$ is unique because $\psi^{1}(\beta)$ is strictly decreasing. Observe that $\beta^{*} \in\left[R(2)-C(0), \beta^{1}\right)$, hence $R(1)-r(0,2)-C(0)>\beta^{*}$ and $R(2)-C(0) \leq \beta^{*}$. Thus, by the condition 1. of Proposition 10 we have $m^{b}=1$. By the condition 2. the firm frontier is $\alpha_{1}^{b}=C^{-1}\left(R(1)-r(0,2)-\beta^{*}\right)$. Finally, the condition 3 . holds because $\int_{0}^{\alpha_{1}^{b}} C(j) d j=2 B$ by construction. Hence, $\beta^{*}$ uniquely satisfies all three conditions of the Proposition 10.

If $(i i)$ is true, then $\psi^{2}\left(\beta^{2}\right)<2 B$ and $\psi^{2}(0)>2 B$, by the assumption of the binding budget constraint. By the Intermediate Value Theorem there exists some $\beta^{*} \in\left(0, \beta^{2}\right)$ such that $\psi^{2}\left(\beta^{*}\right)=2 B$ and furthermore $\beta^{*}$ is unique because $\psi^{2}(\beta)$ is strictly de- 
creasing. Observe that $\beta^{*} \in\left(0, \beta^{2}\right)$, hence $R(2)-C(0)>\beta^{*}$. Thus, by the condition 1. of Proposition 10 we have $m^{b}=2$. By the condition 2. the firm frontiers are $\alpha_{1}^{b}=C^{-1}\left(R(1)-r(0,2)-\beta^{*}\right)$ and $\alpha_{2}^{b}=C^{-1}\left(R(2)-\beta^{*}\right)$. Finally, the condition 3. holds because $\int_{0}^{\alpha_{2}^{b}} C(j) d j+\int_{0}^{\alpha_{1}^{b}} C(j) d j=2 B$ by construction. Hence, $\beta^{*}$ uniquely satisfies all three conditions of the Proposition 10.

Lemma 14. An equilibrium inducing portfolio equivalent to the one characterized in Proposition 10 can always be constructed.

Proof. Either $m=2$ or $m=1$. If $m=1$, then it holds $\int_{0}^{\alpha_{1}^{b}} C(j) d j=2 B$. Then there exists a point $x$ such that $0<x<\alpha_{1}^{b}$ and $\int_{0}^{x} C(j) d j=B$ and $\int_{x}^{\alpha_{1}^{b}} C(j) d j=B$. Let one firm invest in the interval $[0, x)$ and the other firm in the interval $\left[x, \alpha_{1}^{b}\right)$. This investment plan generates a portfolio equivalent to the one characterized.

If $m=2$, then it holds $2 \int_{0}^{\alpha_{2}^{b}} C(j) d j+\int_{\alpha_{2}^{b}}^{\alpha_{1}^{b}} C(j) d j=2 B$. Then there exists a point $x$ such that $\alpha_{2}^{b} \leq x \leq \alpha_{1}^{b}$ and $\int_{0}^{x} C(j) d j=B$ and $\int_{0}^{\alpha_{2}^{b}} C(j) d j+\int_{x}^{\alpha_{1}^{b}} C(j) d j=B$. Let one firm invest in the interval $[0, x)$ and the other firm in the set $\left[0, \alpha_{2}^{b}\right) \cup\left[x, \alpha_{1}^{b}\right)$. This investment plan generates a portfolio equivalent to the one characterized.

Lemma 15. The investment plan constructed in Lemma 14 is an equilibrium and any investment plan inducing the same portfolio is an equilibrium as well.

Proof. The proof is analogous to the proof of Proposition 1, with the opportunity cost equal to $\beta$ as opposed to 0 . 